\title{
Unraveling the Complex Relationship Between Work Transitions and Self-Esteem and Life Satisfaction
}

Anne K. Reitz ${ }^{1}$, Maike Luhmann², Wiebke Bleidorn ${ }^{3}$, and Jaap J. A. Denissen ${ }^{4}$

\author{
${ }^{1}$ Tilburg University \\ ${ }^{2}$ Ruhr University Bochum \\ ${ }^{3}$ University of California Davis \\ ${ }^{4}$ Utrecht University
}

This manuscript was accepted for publication in Journal of Personality and Social Psychology on $03 / 29 / 2022$

\begin{abstract}
Author Note
This research has received funding from the European Union's Horizon 2020 research and innovation programme under the Marie Skłodowska-Curie grant agreement No 846839, awarded to Anne Reitz. We have no conflicts of interest to disclose.

Some of the data appearing in this manuscript were presented at the 2020 conference of the Society for Personality and Social Psychology (SPSP), New Orleans, Louisiana, US.

The preregistration, the analytic methods and code are available on the OSF (https://osf.io/5jkhw/?view only=230c45b8bb5446a9a8d08a6c6b41443f). The data and research material of the LISS data is openly accessible (http://www.lissdata.n1/) and our results and participant selection can be reproduced by running our code on these data.

Correspondence concerning this article should be addressed to Anne K. Reitz, Tilburg University, Department of Developmental Psychology, Simon building S315, PO Box 90153, 5000 LE Tilburg, The Netherlands. Email: A.K.Reitz@ tilburguniversity.edu.
\end{abstract}




\begin{abstract}
Transitions in and out of work are common experiences with major repercussions for people's lives. The complex link between work transitions and psychological adjustment is not well understood, however. In this preregistered study, we analyzed 11 waves of longitudinal data from a representative sample of 13,671 Dutch participants to examine the transactional effects between repeated work transitions (employment and unemployment) and psychological adjustment (self-esteem and life satisfaction). We investigated change trajectories before and after the transitions and tested whether event-related characteristics moderated transition effects. Participants with lower levels of self-esteem and life satisfaction were more likely to experience unemployment and less likely to experience employment transitions, indicating selection effects. Participants decreased in their self-esteem and life satisfaction before the beginning of the unemployment transition, indicating anticipatory effects, with larger decreases in self-esteem for participants who ended up experiencing longer unemployment. We found no consistent effects of employment on changes in life satisfaction or self-esteem, but participants entering more satisfying jobs showed larger increases in life satisfaction. Results were mostly robust when accounting for gender, age, socioeconomic status, and the Big Five traits, and when using propensity-score matching. Effects did not differ among multiple experiences of the same transition. Together, these findings point to dynamic transactions between employment / unemployment and self-esteem / life satisfaction. Findings highlight the importance of closely assessing the specific timing of pre- and post-transition changes and the existence of large individual differences in reactions to work transitions that seem to be partly explained by event-related characteristics.
\end{abstract} Keywords: self-esteem, life satisfaction, employment and unemployment, work transitions, life transitions 


\section{Unraveling the Complex Relationship Between Work Transitions and Self-Esteem and}

\section{Life Satisfaction}

Transitions in and out of work are common experiences in people's lives. Most people have more than one job in their lifetime, many people experience unemployment and some even experience it multiple times over the course of their lifetime, as data from Europe and the US show (Booker \& Sacker, 2012; Herber et al., 2019; Schmillen \& Möller, 2010; U.S. Bureau of Labor Statistics, 2019). Such work transitions have become more prevalent over the last couple of decades due to global labor market transformations and large recessions (OECD, 2020). The COVID-19 pandemic, for example, has triggered one of the worst job crises since the Great Depression with unprecedented global employment losses (OECD, 2020). In 2020, $8.8 \%$ of global working hours were lost relative to the fourth quarter of 2019, equivalent to 255 million full-time jobs (International Labor Organization, 2021).

These trends highlight the importance of understanding people's psychological experience of employment and unemployment transitions. The central role of work for human psychological functioning is well established (Blustein, 2008; Jahoda, 1982; Kohn \& Schooler, 1973; Warr, 1987). Employment has been shown to be beneficial for physical and mental health, and unemployment a potent risk factor for outcomes such as depression, anxiety, mortality, and suicide (Flint, Bartley, Shelton, \& Sacker, 2013; Gebel \& Voßemer, 2014; Thomas, Benzeval, \& Stansfeld, 2005; Warr, 2007; for a meta-analysis, see Paul \& Moser, 2009; for a review, see Wanberg, 2012). In addition to research on clinical outcomes, a growing literature has studied the links between work and psychological adjustment more generally (for meta-analyses, see Luhmann, Hofmann, Eid, \& Lucas, 2012; McKee-Ryan et al., 2005). However, several major questions about the link between work transitions and psychological adjustment remain, and are addressed in this preregistered study. 
The first aim of this study was to investigate the links between psychological adjustment and two important types of work transitions (i.e., changes in employment status): entering a new employment and becoming unemployed. Consistent with theories that stress the importance of dynamic person-environment transactions for individual development (Fraley \& Roberts, 2005; Neyer \& Asendorpf, 2001; Sameroff, 1975), we expected to find bidirectional effects with psychological adjustment predicting work transitions and vice versa. Following the call to take a multidimensional perspective on life transitions (Wagner, Orth, Bleidorn, Hopwood, \& Kandler, 2020), we studied the links between work transitions and two key indicators of psychological adjustment that predict physical and psychological health (Diener, 2009; Orth \& Robins, 2014): self-esteem and life satisfaction. These two constructs are correlated $(r=0.58)$, but also distinct (Lyubomirsky, Tkach, \& Dimatteo, 2006). The distinction between both constructs holds both conceptually (self-esteem is a person's evaluation of their personal value, life satisfaction is a person's overall evaluation of their life) as well as empirically (unique patterns of relations with the other measured variables). The present study provided empirical evidence for another, less studied criterion for exploring their similarity, i.e., their shared environmental antecedents (for criteria to determine sibling constructs; see Lawson \& Robins, 2021).

Previous research has provided first evidence for the link between work transitions and life satisfaction and self-esteem, but conclusions are limited due to the lack of studies using large longitudinal data and rigorous study designs. We therefore examined the longitudinal links between self-esteem and life satisfaction and work transitions using a large 11-year multi-wave data set, allowing us to unravel the longitudinal dynamics with high temporal resolution. Specifically, we examined both directions of effects between work transitions and psychological adjustment: selection (self-esteem and life satisfaction predict the likelihood to experience work transitions) and socialization (work transitions predict 
changes in self-esteem and life satisfaction). As transition-induced change might occur before and after transitions, we distinguish between pre-event (anticipation) and post-event change.

In addition, we investigated the effect of combined and repeated work transitions on self-esteem and life satisfaction. Most studies examined the impact of single unemployment transitions (for an exception, see Luhmann \& Eid, 2009). Work transitions are, however, rarely isolated experiences in real life: reemployment can follow unemployment and unemployment can be experienced repeatedly (U.S. Bureau of Labor Statistics, 2019). It is unknown, however, whether reemployment cancels out the effects of unemployment (interference) and whether people's responses to repeated experiences of the same type of work transition become stronger (sensitization) or weaker (habituation) with each experience.

The first aim of this study was to investigate reasons why individuals differ in their change in self-esteem and life satisfaction in response to work transitions. Knowledge about the sources of individual differences in psychological adjustment is needed to identify people at risk for maladjustment and to develop prevention and intervention programs (e.g., for people who are struggling with the consequences of unemployment). We therefore examined whether event-related characteristics of employment transitions (job satisfaction) and unemployment transitions (unemployment duration) moderated change in self-esteem and life satisfaction. We also explored whether demographic characteristics moderated changes in self-esteem and life satisfaction.

\section{Selection Effects of Self-Esteem and Life Satisfaction on Work Transitions}

Research has provided general support for selection effects of self-esteem (Cetre et al., 2016; Luciano \& Orth, 2017; Orth \& Luciano, 2015) and life satisfaction (Denissen Luhmann, Chung, \& Bleidorn, 2019; Luhmann \& Eid, 2009; Stutzer \& Frey, 2006) and life transitions in important life domains, particularly in the relationship domain. In contrast, less is known about such selection effects for life transitions in the work domain (for an overview 
of exceptions, see Krauss \& Orth, 2021), and in particular for self-esteem, the evidence is inconclusive. Some longitudinal studies indicated that high levels of self-esteem predict later employment (e.g., Salmela-Aro \& Nurmi, 2007). With regard to unemployment, it was found that adolescents with low levels of self-esteem were more likely to be unemployed in young adulthood (an effect that became, however, non-significant when accounting for IQ, depression, and SES; Trzesniewski et al., 2006). A study on the British Household Panel Survey (BHPS) found that low self-esteem predicted unemployment for women but not for men (Huysse-Gaytandjieva, Groot, Pavlova, \& Joling, 2015). In contrast, another study found no selection effects for unemployment (Tetzner, Becker, \& Baumert, 2016).

There is some evidence to suggest that life satisfaction predicts unemployment. Longitudinal research on panel studies reported that dissatisfied (versus satisfied) individuals were more likely to lose their job (Clark, 2003; Graham et al., 2004; Luhmann \& Eid, 2009). One previous analysis on parts of the present data reported that individuals who experienced unemployment had lower life satisfaction than those who did not experience unemployment (Denissen et al., 2019). For employment, evidence is lacking, with the exception of one study that found that higher life satisfaction was associated with a higher likelihood of starting a new job (Luhmann, Lucas, Eid, \& Diener, 2013).

In summary, theory and some research indicates that self-esteem and life satisfaction predict work transitions. Based on this literature, we anticipated that higher levels of selfesteem and life satisfaction predict a lower likelihood of experiencing unemployment $(\mathrm{H} 1.1)$ and a higher likelihood of experiencing employment (H1.2).

\section{Socialization Effects of Work Transitions on Self-esteem and Life Satisfaction}

Both self-esteem (Donnellan et al., 2012; Kuster \& Orth, 2013; Trzesniewski et al., 2003) and life satisfaction (Eid \& Diener, 2004; Lucas \& Donnellan, 2007) show substantial rank-order stability (consistency) over time. Yet, research also found considerable rank-order 
changes and individual variability in change trajectories (for self-esteem, see Reitz, Shrout, Denissen, Dufner, \& Bolger, 2020; for life satisfaction, see Lucas \& Donnellan, 2007) and mean-level changes across the lifespan (for self-esteem, see Orth, Erol, \& Luciano, 2018; for life satisfaction, see Baird et al., 2010; Hudson, Lucas, \& Donnellan, 2017). Together, these findings suggest that self-esteem and life satisfaction are changeable.

In the wake of these findings, there has been an increasing interest in identifying the factors and processes that elicit change in self-esteem and life satisfaction (i.e., socialization effects). Lifespan theory and other transactional perspectives have posited that environmental changes can trigger developmental change in broad traits (Baltes, Lindenberger, \& Staudinger, 2006; Elder, 1998; Roberts et al., 2005; Sameroff, 2010). According to these perspectives, major life events can elicit change in self-esteem and life satisfaction as they bring various changes in the environment, which has generally been supported (Bleidorn, Hopwood, \& Lucas, 2018; Denissen et al., 2019; Lucas, 2007). Life events in the work domain might be an important catalyst of psychological change as work is of central importance for people's basic needs (Blustein, 2008; Jahoda, 1982; Van den Broeck, Ferris, Chang, \& Rosen, 2016). Work transitions provide a unique opportunity to study the predictions of lifespan theory and other transactional perspectives because they bring about changes in the environment that might be major sources of self-esteem and life satisfaction. Self-esteem theories predict that work transitions can influence self-esteem, too. Selfesteem is considered to rise and fall in response to one's subjective experience of success and failure (Crocker \& Wolfe, 2001; Hogan \& Roberts, 2004; James, 1890). Several scholars consider self-esteem to be responsive to mastery experiences (Leary \& Baumeister, 2000; Wojciszke, Baryla, Parzuchowski, Szymkow, \& Abele, 2011). Research testing these predictions for work transitions is scarce and evidence is mixed and indirect. A study found changes in employment status and income to be related to decreases in self-esteem in older 
adults (Orth, Trzesniewski, \& Robins, 2010). Another study found that first-time employed increased in self-esteem; the mean-level change was, however, comparable to those not yet employed after graduation (Reitz et al., 2020). However, other studies found no links between employment status and self-esteem (Kuster, Orth, \& Meier, 2013).

Set-point models of subjective well-being (e.g., Lykken \& Tellegen, 1996) predict that life satisfaction changes temporarily in reaction to life events and returns to baseline levels over time, but research has shown that long-term change in life satisfaction is possible (Diener, Lucas, \& Sollon, 2006). Longitudinal studies have consistently reported negative effects of unemployment on life satisfaction (Clark, Georgellis, \& Sanfey, 2001; Lucas, 2007; McKee-Ryan et al., 2005; Winkelmann \& Winkelmann, 1998). One of the first largescale longitudinal study on this topic used the German Socio-Economic Panel (SOEP) and concluded that unemployment might permanently change life satisfaction (Lucas, Clark, Georgellis, \& Diener, 2004). A meta-analysis of longitudinal studies reported negative effects of unemployment on life satisfaction, but cautioned that many studies were conducted a long time ago (Luhmann et al., 2012). The authors reported a non-linear trajectory: a negative initial reaction was followed by an increase (rebound), which, however, did not balance out the initial negative reaction until three years after the event (see also Denissen et al., 2019).

An important unanswered question in the literature is at what point in time changes due to work transitions begin. Theoretical perspectives on personality development consider the possibility that changes start before the life event begins, as people might already engage in psychological investments when anticipating life transitions (Roberts et al., 2005). Studies using the SOEP have reported pre-event declines in life satisfaction (Clark, Diener, Georgellis, \& Lucas, 2008; Hahn et al., 2015; Oesch \& Lipps, 2013; for a meta-analysis, see Luhmann et al., 2012; which are commonly referred to as anticipatory effects, even if expectations are not directly assessed). However, another study did not find anticipatory 
effects (von Scheve, Esche, \& Schupp, 2017). Anticipatory effects of unemployment on life satisfaction need to be replicated, especially in countries other than Germany. Also, such effects should be explored for self-esteem and employment, for which evidence is lacking.

Previous research has not yet consistently disentangled anticipatory effects from selection and post-event socialization effects. For at least two reasons, the distinction between these effects is of great importance to accurately interpret the results from prospective studies. First, if anticipatory changes are ignored, one might draw incorrect conclusions about post-event socialization effects. For example, if adjustment levels decrease before unemployment but do not drop any more after, one might falsely interpret this as an absence of change. Second, disentangling anticipatory effects from selection effects is necessary to avoid false conclusions about the predictive validity of self-esteem and life satisfaction. For example, low levels self-esteem prior to unemployment could either indicate selection effects (individuals with low self-esteem are more likely to experience unemployment) or anticipatory effects (people's self-esteem tends to decrease during the time leading up to unemployment). To disentangle these effects, we analyzed self-esteem and lifesatisfaction across multiple assessments before and after the relevant work transitions.

In summary, based on previous theory and research, we expected socialization effects: The transition to unemployment will predict decreases in self-esteem and life satisfaction (H2.1) and the transition to employment will predict increases in self-esteem and life satisfaction (H2.2). To examine the precise timeline of change, we explored both anticipatory (pre-event) and post-event change as distinguishable parts of socialization effects.

\section{The Effects of Multiple Work Transitions on Self-Esteem and Life Satisfaction}

Research has almost exclusively focused on single occurrences of either employment or unemployment. However, these work transitions are not isolated instances. We therefore explored two ways in which their effects might be intertwined. First, people may experience 
transitions in and out of employment within short periods of time. The effects of a later transition may interfere with the effects of a prior transition, which is why we examined combined effects. Second, many people experience multiple transitions of the same type, and their responses to later transitions may differ from responses to earlier transitions (sensitization or habituation), which is why we examined repeated transitions. In the following, we describe these possibilities in more detail.

\section{Combined Effects of Employment and Unemployment Transitions}

Experiencing a sequence of employment and unemployment transitions may lead to multiple layers of effects on self-esteem and life satisfaction. However, most existing research has not disentangled their combined effects. Similar to interference, a physical phenomenon in which two waves come together to form a new wave, an accurate estimate of an event requires accounting for the effects of previous events. For example, a positive effect of speedy reemployment might cancel out the negative effect of unemployment and quickly losing one's job might result in an attenuated positive effect of a new employment. Interference might also result in illusory effects, for example when a rebound in adjustment following unemployment is due to universal factors (e.g., setpoint effects) but is mistaken for a positive effect of reemployment if it occurs soon after. To the extent that employment and unemployment frequently occur closely together, and both have distinctive effects, accounting for interference should result in more pronounced and/or robust effect size estimates.

Research on the effect of reemployment on self-esteem is scarce and has not been able to statistically tease apart unemployment and reemployment. One challenge of many studies is that they used retrospective reports instead of assessing change from unemployment to employment. A meta-analysis found that reemployment was associated with an improvement of mental health (self-esteem was one of six indicators; Paul \& Moser, 
2009). The magnitude of the positive effects of reemployment was larger than the magnitude of the negative effects of unemployment (for similar findings, see McKee-Ryan et al. 2005). However, when corrected for testing effects (a systematic change of test scores caused by repeated measurement), Paul and Moser (2009) found that the effect sizes for unemployment and reemployment became more similar. We therefore accounted for testing effects.

Research on life satisfaction has not yet provided conclusive results. Some studies have reported that people increased in life satisfaction after reemployment but did not return to their pre-unemployment levels (Clark et al., 2001; Luhmann \& Eid, 2009). A metaanalysis on mostly prospective studies has surprisingly reported that the initial impact of reemployment on life satisfaction was negative (Luhmann et al., 2012). The authors speculated that the actual experience of reemployment might have been less positive than anticipated and therefore called for studies that account for anticipatory changes of reemployment. It might also be that formerly unemployed individuals were still recovering from that experience when they became reemployed, which is why the authors emphasized the need to tease these effects apart. Moreover, as most studies on combined effects used the SOEP data (with country-specific (long) unemployment durations and reemployment patterns), studies from other countries are needed to examine their generalizability.

\section{Repeated Employment and Unemployment Transitions}

A substantive number of people experience multiple unemployment spells in their lifetime. Data from the US and Germany suggest an average of 1.5 and 1.6 unemployment spells across 3- and 25-year periods, respectively (Palumbo, 2010; Schmillen \& Möller, 2010). Of those reporting unemployment, $15 \%$ reported two, and 3\% three or more spells during the 17 years of the BHPS (Booker \& Sacker, 2012). Nevertheless, little is known about whether or not the effects of work transitions are similar when experienced repeatedly. The stress-sensitization model predicts that repeated exposure to negative experiences results 
in increasingly negative effects on psychological adjustment (Monroe \& Harkness, 2005). Similarly, the stress-accumulation model predicts more intense reactions after repeated unemployment spells due to an accumulation of stress factors such as financial and social deprivation (Warr, 1987). Contrasting predictions can be derived from theories of adaptation or habituation: People might respond less intensely with each new work transition as people handle adversity increasingly well (Frederick \& Loewenstein, 1999).

Research on repeated work transitions is still in its infancy. A study using the SOEP reported that the decline in life satisfaction was the same each time, but because people did not return to their pre-unemployment level during reemployment, their life satisfaction decreased (in a stepwise fashion) from unemployment to unemployment (Luhmann \& Eid, 2009). A study using the BHPS also reported that psychological well-being levels were lower at each unemployment spell (Booker \& Sacker, 2012). However, neither study included a comparison group nor accounted for testing effects. Replications of the effects of repeated unemployment spells on life satisfaction that account for testing effects are needed to obtain robust effects. Furthermore, it is important to examine other psychological outcomes, such as self-esteem, as well as the impact of repeated employment transitions.

In summary, based on previous theory and research, we explored combined effects of employment and unemployment transitions and examined whether the effects of employment and unemployment changed with repeated experiences (sensitization or habituation). Based on the notion that personality characteristics might predispose individuals to have more erratic work lives (Caspi, Bem, \& Elder, 1989), we also explored whether self-esteem and life satisfaction predicted the likelihood of experiencing repeated work transitions.

\section{Event-Related Characteristics as Moderators of Socialization Effects}

Several studies found considerable interindividual differences in the change of selfesteem and life satisfaction in response to work transitions (Doré \& Bolger, 2018; Lucas, 
2007; Luhmann \& Eid, 2009; Reitz et al., 2020). Previous research has predominantly focused on personality and socio-economic factors as sources of this heterogeneity, while less is known about the moderating role of event-related characteristics (Yap, Anusic, \& Lucas, 2012; see Eid \& Larsen, 2008; McKee-Ryan et al., 2005). However, the quality of life transitions can vary tremendously and likely bring about unique psychological experiences (Lodi-Smith \& Roberts, 2007; Luhmann, Fassbender, Alcock, \& Haehner, 2020). While most people consider employment as a positive event, some people may be unhappy with their job or feel overwhelmed by the new challenges and responsibilities. Similarly, while most people consider unemployment as a negative event, a brief spell might not be such a negative experience if a new job is already on the horizon. Nevertheless, the literature often categorizes a certain life transition as either a positive or a negative experience, thus ignoring the quality or subjective valence of the experience. This valence, however, may shape an individual's response to the event (e.g., Luhmann et al., 2020; for a recent study that demonstrated that for bereavement, see Reitz et al., 2022). We therefore examined peoples' job satisfaction and the duration of unemployment as moderators of changes in self-esteem and life satisfaction.

\section{Job Satisfaction}

Job satisfaction, a central evaluative characteristic of the work experience, might moderate the effects of employment and unemployment on self-esteem and life satisfaction. Self-esteem is positively related to job satisfaction (for a meta-analysis, see Judge \& Bono, 2001). Job satisfaction prospectively predicted self-esteem in one of two samples in one study (Kuster et al., 2013), whereas no effects were found in another study (Orth, Robins, \& Widaman, 2012). A study on within-person change found that an increase in positive achievement-related daily experiences was linked to an increase in self-esteem during the education-to-work transition (Reitz et al., 2020). This finding is in line with the notion that 
self-esteem levels fluctuate in response to good and bad experiences (Crocker \& Wolfe, 2001; James, 1890). Hence, positive employment effects on self-esteem may be amplified for people who are satisfied with their jobs. Conversely, the negative effects of unemployment might be amplified for people who lose a job they were satisfied with.

Job satisfaction might also moderate effects of work transitions on life satisfaction. Research has reported a link between job satisfaction and life satisfaction (see Bowling, Eschleman, \& Wang , 2010), which is consistent with the hypothesis that job experiences spill over into other areas of life (Heller, Judge, \& Watson, 2002). People who are more satisfied with their new job can thus be expected to report higher life satisfaction in response to a new job. The reverse might be true for unemployment: People who are more satisfied with their previous job should report lower life satisfaction in response to losing this job. We therefore expected larger increases in self-esteem and life satisfaction when starting a satisfying job and larger decreases when terminating a satisfying job (H3.1).

\section{Unemployment Duration}

A number of researchers have argued that longer periods of unemployment may have more negative psychological consequences due to cumulative stress processes (e.g., increasing financial pressures, diminishing coping resources, frustrations from failed job seeking; Kinicki, Prussia, \& McKee-Ryan, 2000; Kroft, Lange, Notowidigdo, \& Katz, 2016; Warr, Jackson, \& Bancks, 1982). Consistent with this position, studies found that longer unemployment spells had more negative effects on mental health (McKee-Ryan et al., 2005; Paul \& Moser, 2009) and life satisfaction (Hahn et al., 2015; Luhmann \& Eid, 2009).

Other researchers have argued that individuals may be likely to adapt to even long spells of unemployment as they learn to deal with the circumstances (e.g., by budgeting and dropping inefficient job search strategies; see Clark, 2006). While this notion conflates unemployment duration and time passed since the event (regardless of whether it triggered a 
short versus long spell), there is some evidence to support this idea (for a review see Clark, 2006). However, these studies were mostly based on cross-sectional or retrospective data and operationalized duration as a person's total lifetime spent unemployed, which does not capture the duration of specific unemployment spells. Another set of studies reported no effects of unemployment duration on life satisfaction (Winkelmann \& Winkelmann, 1998; Winkelmann, 2009). A reason why the latter findings differ from those from most other studies might be methodological (a cutoff of more versus less than two months).

In sum, research provided mixed evidence for the moderating effect of unemployment duration. While studies that employ stricter statistical controls found that longer spells predict a stronger decrease in psychological well-being, studies with less strict controls reported inconsistent evidence. Because the current study applied statistical procedures that were as stringent (if not more stringent) as the former group of studies, we predicted greater decreases in self-esteem and life satisfaction for longer versus shorter spells of unemployment (H3.2).

\section{Personal Characteristics as Moderators and Covariates}

In addition to event-related characteristics, we examined the role of personal characteristics in the links between self-esteem, life satisfaction, and work transitions. First, self-esteem and life satisfaction might be associated with work transitions partly because of a confound that is relatively stable and independent of the environmental circumstances. Broad personality traits - such as the Big Five traits extraversion, neuroticism, openness, agreeableness, and conscientiousness - might shape or even partly explain the links between work transitions and both self-esteem and life satisfaction. Personality traits have been reliably linked with individual differences in self-esteem (Robins, Tracy, Trzesniewski, Potter, \& Gosling, 2001) and life satisfaction (Anglim, Horwood, Smillie, Marrero, \& Wood, 2020), and were found to predict work transitions including new employment and unemployment (Denissen et al., 2019; Roberts, Kuncel, Shiner, Caspi, \& Goldberg, 2007). 
To the degree that the links between self-esteem and life satisfaction and work transitions are a function of personality trait differences, accounting for personality trait differences should reduce the direct association between work transitions and self-esteem and life satisfaction.

Second, demographic factors may play a role in the links between work transitions, self-esteem, and life satisfaction. Specifically, women and older workers have a higher risk of unemployment (International Labor Organization, 2021). To account for this heterogeneity, we include age and gender in all models as covariates. Furthermore, there is evidence that age, gender, and socioeconomic status (SES) are linked with self-esteem and life satisfaction (Diener, 2009; Robins, Hendin, \& Trzesniewski, 2001; Sinclair et al., 2010). In the Netherlands, unemployment effects were found to vary depending on gender and age (MooiReci \& Ganzeboom, 2014). We therefore explored whether the association between work transitions and self-esteem and life satisfaction was moderated by age, gender, and SES.

\section{The Present Study}

The present study examined the complex links between work transitions (two changes in employment status: becoming employed and becoming unemployed) and psychological adjustment (self-esteem and life satisfaction) to address several unanswered questions. Our first aim was to investigate their bidirectional association that is predicted by transactional views. We expected to find selection effects: self-esteem and life satisfaction should predict a lower likelihood of unemployment (H1.1) and a higher likelihood of employment (H1.2). Furthermore, we expected to find socialization effects: the unemployment transition predicts a decrease (H2.1) and the employment transition predicts an increase in self-esteem and life satisfaction (H2.2). As employment and unemployment rarely occur as isolated events, we examined the impact of multiple transitions. Specifically, we examined combined effects of employment and unemployment and whether self-esteem and life satisfaction showed sensitization (responding more strongly) or habituation (responding less strongly) after 
repetitions of the same transition. We furthermore explored selection effects for repeated transitions.

Our second aim was to investigate sources of interindividual differences in change in self-esteem and life satisfaction due to work transitions. Based on theory and research, we identified two event-related characteristics of work transitions that might shape socialization effects. We predicted that individuals with higher (versus lower) levels of job satisfaction show stronger positive effects when they enter their job and stronger negative effects when they lose their job (H3.1). In addition, we predicted that the decline in self-esteem and life satisfaction is more pronounced for longer (versus shorter) unemployment spells (H3.2). Finally, we explored whether age, gender, and SES moderate effects.

The present study used a design that overcomes several methodological challenges in previous research (see Bleidorn et al., 2018; Luhmann, Orth, Specht, Kandler, \& Lucas, 2014). First, most studies relied on data with only a few assessments with relatively large time lags between them that prohibit examining the precise timeline and shape of change trajectories. We used a prospective design with multiple, rather fine-grained assessments of employment status (every month), self-esteem (every 1 to 2 years) and life satisfaction (every year), which provided novel insights into the specific non-linear change trajectories. Second, most studies placed the first assessment shortly before or at the time of the transition, which cannot capture anticipatory changes but mistakes them for stable pre-existing differences. To disentangle anticipatory from selection and post-event effects, we started several years before the work transition and examined these effects simultaneously. Third, most studies covered only a few years, which is not long enough to separate short-term from long-term or baseline change and to capture repeated transitions. In contrast, we covered a period of up to 11 years.

We used multilevel modeling to estimate the specific change trajectories, to model individual differences in change, and to capture the effects of multiple work transitions. We 
preregistered our hypotheses and the data analytic strategy and made the code of the data analysis available on the Open Science Framework (OSF). To examine the robustness of effects, we included age and gender as covariates. We also ran exploratory robustness tests that used the Big Five traits as covariates and propensity-score matched comparison groups.

\section{Method}

\section{Procedure}

Data for this study came from the Longitudinal Internet Studies for the Social Sciences (LISS) panel. The LISS panel follows a representative probability sample of Dutch households drawn from the population register by Statistics Netherlands (Scherpenzeel \& Das, 2010). Participants were recruited by letter, followed by a telephone call and/or house visit, and had to complete online questionnaires (for detailed information on the sample, recruitment, and materials, see https://www.lissdata.nl/about-panel). To counteract attrition, new participants are included in the panel on a regular basis (Lugtig, 2014). The present study is exempt from Institutional Review Board approval because it uses a publicly available de-identified archival dataset.

We used data from the 11 waves that were available at the time of conducting the analyses. The first data collection was in 2008 and the last used collection in 2019. The first cohort assessed in 2008 was the largest and has been, naturally, participating the longest (11 years). Participants provided demographic information on a monthly basis, which we used to code experiences of work transitions. Participants completed the life satisfaction questionnaires every year and self-esteem questionnaires in most but not all years (assessments were a maximum of two years apart) in a planned missingness design. The exact pattern of planned missingness depended on the year of sample entry (i.e., a cohort; see Tables S1 and S2 of the supplementary materials for an overview of the sample sizes for each cohort per assessment year). We calibrated the time axis according to the timing of events, 
with 0 representing the time of the event, with negative values indicating the number of months before the event and with positive values indicating the number of months after the event. This approach makes it less relevant that certain waves or years were missing (as compared to an analytic strategy that uses "year" or "measurement wave" as time axis).

\section{Participants}

The existing data set had a total pool of over 22,000 participants. We included data from participants who completed at least one self-esteem or life satisfaction survey (individuals with only one assessment contributed to the estimation of the intercept). This resulted in a sample of 13,671 participants. The average age of participants at the first assessment was 43.62 years $(S D=17.74)$ and $54 \%$ of the participants were female. Regarding highest educational attainment, $8 \%$ reported primary school, 22\% VMBO (akin to junior high school), 11\% HAVO/VWO (akin to senior high school), 22\% MBO (akin to junior college), $21 \%$ HBO (akin to college), and 9\% university. Regarding monthly income after taxes, $15 \%$ reported no income, $8 \%$ less than $500 €, 16 \%$ between $501 €$ and $1000 €, 19 \%$ between $1001 €$ and $1500 €, 21 \%$ between $1501 €$ and $2000 €, 10 \%$ between $2001 €$ and $2500 €$, $5 \%$ between $2501 €$ and $3000 €$, and 3\% 3001€ or higher. Eighty-three percent had a Dutch heritage (for percentages per variable and group, see Tables S3 and S4 of the supplementary materials). Other ethnicities were other Western, Indonesian, Turkish, Dutch Antilles, Surinamese, Moroccan (for more information on the ethnic composition of the LISS panel; see Knoef \& de Vos, 2009). A detailed description of the full sample can be found online.

The preregistration of the hypotheses, the data analytic strategy, and the R code of the data analysis are available on the OSF (https://osf.io/5jkhw/?view_only=230c45b8bb5446a9a8d08a6c6b41443f; deviations from the final study from the registration are shown in Table S5 of the supplementary materials). The LISS data is openly accessible and our results and participant selection can be reproduced by 
running our code on these data. A recent study used the LISS data from 2008-2017 to examine the links between first-occurrence life events (including work transitions) and Big Five personality traits (Denissen et al., 2019). This study included life satisfaction (to compare the effects for the Big Five traits with), but in contrast to our study it did not include self-esteem, multiple work transitions, the 2018-2019 data, nor the moderators. Another study used the LISS data to examine cross-sectional correlations between employment status and self-esteem and life satisfaction (van der Meer \& Wielers, 2016).

\section{Measures}

\section{Self-Esteem}

Self-esteem was assessed with the 10-item Rosenberg Self-Esteem Scale (Rosenberg, 1965). Participants rated their agreement with statements such as "On the whole I am satisfied with myself" on a 7-point Likert scale ranging from strongly disagree (1) to strongly agree (7). The scale's internal consistency (coefficient alpha) was .90 across years.

\section{Life Satisfaction}

Life satisfaction was measured using the 5-item Diener Satisfaction with Life Scale (Diener, Emmons, Larsen, \& Griffin, 1985). Responses to statements such as "In most ways my life is close to my ideal" were assessed on a 7-point Likert scale ranging from strongly disagree (1) to strongly agree (7). The average coefficient alpha was .89 across years.

\section{Work Transitions}

Work transitions were derived from the employment statuses of the monthly demographic surveys. We created dummy variables to indicate the experience of new employment and unemployment based on a month-to-month comparison of participants' primary occupation status. When participants reported a change into one of these answer options from one month to the next, we marked the month in which the change had taken place with two dummy variables. A " 1 " on the first dummy indicated the employment 
transition: the beginning of paid employment (about one third each was previously employed, a student, or other, including home keeper, freelancer, voluntary activity). A "1" on the second dummy indicated the unemployment transition: becoming a job seeker following job loss. We created dummies for the first, second, and third occurrence of unemployment and employment in the study period. The prevalence of each type of event decreased considerably with each repetition, which is why we restricted our analyses to three repetitions.

Tables S6 and S7 of the supplementary materials show the sample sizes per assessment wave for different work transitions for self-esteem and life satisfaction, respectively. Table S8 of the supplementary materials shows demographic differences between participants who experienced an employment transition $(N=1,819)$ and those who did not experience an employment transition and reported a work status at any point while in the LISS panel (mostly people who entered the sample while being employed; $N=5,633$ ). Table S9 of the supplementary materials shows demographic differences between participants who experienced an unemployment transition $(N=933)$ and those who did not experience an unemployment transition and reported a work status at any point while in the LISS panel $(N=6,508)$.

\section{Time Coefficients Capturing Mean-Level Change}

We adopted the recommendations by Luhmann and Eid (2012) and computed four time coefficients (i.e., time-variant event parameters) to model within-person changes in selfesteem and life satisfaction (see Figure S10 of the supplementary materials for an illustration). We included one pre-event change coefficient (preLin) and three post-event change coefficients: postYear indicating sudden but short-term (non-lasting) changes, postBase indicating baseline changes, and postLin indicating gradual (linear) changes:

(1) The linear anticipation coefficient (preLin) reflects the rate of linear change in the outcome variable leading up to the first transition. The monthly metric was converted to a 5- 
year (60 months) metric to reduce range differences between indicators (also done for the postLin coefficient $)^{1}$. All occasions preceding the transition (e.g., -1 if a self-esteem or life satisfaction assessment happened 5 years before the event) have negative values that count upwards to 0 until the time of the transition, after which all occasions were coded as 0 .

(2) The post-event year coefficient (postYear) indicates a sudden short-term change in the outcome. PostYear was coded as a dummy variable with 1 marking any self-esteem or life satisfaction assessment within one year after the transition and 0 for all other occasions.

(3) The post-event baseline change coefficient (postBase) represents a sudden baseline shift after the transition. PostBase can be interpreted as a baseline change in the outcome variable (for the duration of the study), beyond short-term changes. PostBase is coded as a dummy variable with a value of 1 for any self-esteem or life satisfaction assessment after the transition, and 0 for all occasions before the transition.

(4) The post-event linear coefficient (postLin) reflects the rate of linear change in the outcome variable after the transition, beyond short-term changes and baseline change. All occasions preceding the transition were coded with 0 , and all occasions after the transition have positive values that count upwards (e.g., 1 if a self-esteem or life satisfaction assessment happened 5 years after the transition $)^{1}$.

For the comparison groups (which is the case for the original comparison groups and the propensity-score matched comparison groups added following a reviewer comment ${ }^{2}$ ), all time coefficients were coded with 0 on all occasions. As a result, these coefficients represent changes in the transition sample over and above those experienced by other participants. The intercept estimates the predicted level of the outcome variable for an individual of average age and gender who has never experienced the transition, at the first measurement occasion.

\section{Event-Related Characteristics}


Job Satisfaction. Job satisfaction was assessed with five items. Participants indicated how satisfied they were with "your wages or salary or profit earnings", "your working hours", "the type of work that you do", "the general atmosphere among your colleagues", and "with your current work". The scale ranged from not at all satisfied (0) to fully satisfied (10). The scale also contained a sixth item "your career so far", which we excluded because we were interested in participants' current or previous job instead of their career in general. The average coefficient alpha was .83. If multiple satisfaction measures were available for a specific job, the average was taken. For plotting the results, we formed a binary job satisfaction variable using a mean-level split (lower satisfaction (0), higher satisfaction (1)).

Unemployment Duration. Duration of unemployment was derived from the event variable described above. We computed duration as the number of months from beginning to end of the transition. We log-transformed the duration variable, because many more individuals experienced short-term unemployment than long-term unemployment (producing skewness). For plotting the results, we formed a binary duration variable (0-12 months (0), 12 months or more (1)).

\section{Demographic Variables}

Age was included as a linear covariate (grand-mean centered at age 43.62). We divided it by five to create a metric similar to the linear event-related time coefficients (i.e., 1 $=5$ years/60 months). We also included age as a squared covariate. To avoid that the range of the quadratic term deviated strongly from the linear term, quadratic terms were divided by 10, which makes them also easier to interpret and the scaling more comparable to the other variables (cf. Clark, Flèche, \& Senik, 2016). In addition, female gender (male (0), female (1)) was added as a covariate.

We examined the moderating effects of person-level (time-invariant) demographic characteristics of the socialization effect in separate analyses as they were reported at the 
beginning of the survey: gender, age, education level, income level, and occupational prestige. As education, occupational prestige, and income were not continuous and the income variable was skewed, we dichotomized them. Education was measured using a categorical variable indicating the highest diploma obtained. Consistent with common statistical practice in the Netherlands (CBS, 2021), we coded participants with college and/or university as "highly educated" (29\%) and the remaining participants as "low to medium educated" (71\%). Furthermore, we coded "other mental work", "skilled and supervisory manual work", "semi-skilled manual work", "unskilled and trained manual work", and "agrarian profession" as lower occupational prestige (51\%) and "higher academic or independent profession", "higher supervisory profession", "intermediate academic or independent profession", and "intermediate supervisory or commercial profession" as higher occupational prestige (49\%). Finally, we created a dummy variable indicating lower income with a value of 0 for all individuals earning $1500 €$ monthly or less (51\%), and a 1 indicating higher income for all individuals earning $1501 €$ or more (49\%).

\section{Personality}

The Big Five traits (extraversion, agreeableness, conscientiousness, emotional stability, openness to experience) were assessed with the 50-item version of the IPIP BigFive inventory (Goldberg, 1992). Participants rated their agreement with self-describing statements on a 5-point scale ranging from 1 (very inaccurate) to 5 (very accurate). The average coefficient alpha was .82 across years.

\section{Analytic Strategy}

Measurement occasions (Level 1) were nested within persons (Level 2), which in turn were nested within households (Level 3). To account for the nested structure, we analyzed the data using multilevel models using the lme4 package (Version 1.1-21; Bates, Mächler, Bolker, \& Walker, 2014) in R (Version 3.6.3; R Core Team, 2020). Self-esteem, life 
satisfaction, and job satisfaction were grand-mean standardized (i.e., in the long format).

Effects therefore resemble effect sizes (Cohen's $d$ ) in the case of the dummy predictors, for example, a value of 1 indicates that the difference between groups equaled $1 S D$. Effects for continuous predictors can be interpreted as a change in $S D$ units of the outcome variable for every 1-unit increment of the predictor (e.g., corresponding to a five-year increment in the case of the event timing and age variables). Analyses were first conducted separately for selfesteem and life satisfaction and for employment and unemployment. The rationale for starting with a separate analysis is that not everybody who transitioned out of unemployment went back into employment, and not everyone who transitioned into employment has previously been unemployed. In addition to fixed effects, we modeled random intercepts for households, persons, and measurement occasions (when analyzing repeated transitions). The latter random effect was added because the dependent variable (but not the independent variables) was identical within measurement occasions.

We accounted for linear and quadratic age, gender, and testing effects in all models. The testing effects variable accounted for changes in self-esteem and life satisfaction scores that were due to the repeated assessments. We modeled testing effects as linear changes in the form of a function of the number of previous self-esteem and life satisfaction assessments ( 0 for the first assessment, 1 for the second assessment, and so forth; for a similar approach see McArdle, Ferrer-Caja, Hamagami, \& Woodcock, 2002).

\section{Combined Employment and Unemployment Transitions}

After examining the effects of employment and unemployment separately, we examined them in one model. This combined analysis disentangles the effects of interlocking time effects. Consider this example: Someone recovers from decreased life satisfaction after becoming unemployed and eventually finds a new job. Is the recovery due to the dissipation of the short-term effect of unemployment, or to the new job that exerts a positive effect? For 
these analyses, we added all time coefficients of the first occurrence of both work transitions to a regression equation predicting self-esteem or life satisfaction.

\section{Repeated Work Transitions}

We also investigated whether repeated transitions had different effects on self-esteem and life satisfaction. We created two data frames: one consisting of measurements of individuals who had experienced at least one transition into paid employment during the study, and another one consisting of measurements of individuals who had experienced at least one transition into unemployment. For up to three (repeated) transitions, separate rows were created with information about self-esteem and life satisfaction at each measurement occasion, and the relative position of each occasion compared to the (repeated) transition in question, as indicated by the time coefficients described above. Table S11 of the supplementary materials shows an example of the coding of the time coefficients for the different repetitions of employment transitions for life satisfaction for one fictitious individual.

\section{Time-Invariant Effects Indicating Preexisting Differences}

We created a time-invariant dummy variable Event Selection with a value of 1 for participants who had ever experienced the transition (i.e., had been employed/unemployed at least once in our sample) and with 0 for those who did not (neither before nor during the study). The effect of this dummy variable indicates differences between those who will experience a transition and those who will not, which were interpreted as selection effects.

\section{Moderator Analyses}

We examined the extent to which the reaction to the employment and unemployment transitions (i.e., socialization effects) varied as a function of job satisfaction and duration of unemployment. We additionally explored gender, age, initial education level, initial income, and initial occupational prestige as Level 2 moderators. 


\section{Inference Criteria and Power Considerations}

Our statistical tests were dependent, as the same outcome variable and events were used in multiple comparisons. Because of the relatively large number of statistical tests, we controlled for the false discovery rate using the "BY" method (Benjamini \& Yekutieli, 2001), which accounts for dependency. We did this within each major group of hypotheses, with separate corrections for primary hypotheses versus more exploratory analyses. For details about these various correction procedures, we refer to the R scripts uploaded to OSF. We computed $99.9 \%$ confidence intervals for a lack of a uniform corrected level, so the significance levels do not correspond to the confidence intervals (they approximately correspond to the corrected, but not raw $p$-value).

Because we employed secondary data analysis, we were unable to determine the sample size a priori using power analysis. Instead, we performed a posthoc sensitivity power analysis using the simr package, which starts with a model estimate obtained with the actual data and uses observed parameters (e.g., correlations between random effects) to simulate additional datasets. For these simulations, the user can specify effect sizes for selected coefficients and then compute the power with which these effect sizes could be detected. Because this simulation approach is very computationally intensive, it was focused on the "power bottleneck": the parameter that is calculated on the smallest number of datapoints and therefore has the lowest power. This was the postYear parameter, which is typically only based on a single data point. Because unemployment occurs less frequently than unemployment in the LISS dataset and we have fewer self-esteem than life satisfaction assessments, the postYear effect for unemployment and self-esteem represents the bottleneck. Because we focused on the first repetition in our main analyses, our power analysis focused on the first unemployment transition. We had $74 \%$ power to detect an effect size of $d=.15$ for a first postYear effect on self-esteem, and 98\% power to detect an effect size of $d=.20$. 


\section{Results}

\section{Descriptive Statistics}

The means and standard deviations across all available waves were: $M(S D)=5.52$ (1.02) for self-esteem, $M(S D)=5.05$ (1.11) for life satisfaction, $M(S D)=6.64$ (1.09) for job satisfaction, and $M(S D)=12.72$ (14.6) for unemployment duration (in months; see Table S12 of the supplementary materials for the means and standard deviations for all waves). The correlations between the study variables were (minimum / maximum correlation across all measurement waves): $r=.43 / .49$ for self-esteem and life satisfaction, $r=.22 / .39$ for selfesteem and job satisfaction ${ }^{3}$, and $.32 / .57$ for life satisfaction and job satisfaction. The duration of the first unemployment (which we used as moderator variable) did not correlate significantly with the average satisfaction with the lost job or the average levels of selfesteem and life satisfaction during the study, $p \geq .06$. At the first employment transition, the average age was $M(S D)=35.28(13.18)$ and $61 \%$ were female. At the first unemployment transition, the average age was $M(S D)=43.19(12.40)$ and $55 \%$ were female. The average time between the first and second occurrences was 30 months for employment and 25 months for unemployment (time between second and third occurrences were 22 and 21 months).

\section{Selection Effects of Self-esteem and Life Satisfaction on Work Transitions}

We first examined selection effects for the first employment and unemployment transitions that people experienced during the study period (see Table 1). We found selection effects both for employment and unemployment and for both self-esteem and life satisfaction. Confirming H1.1 and H1.2, participants with higher levels of self-esteem and life satisfaction were more likely to become employed ( $b=.19$ and $b=.12$, respectively) and less likely to become unemployed ( $b=-.16$ and $b=-.32$, respectively). These coefficients can be interpreted as effect sizes (Cohen's $d$ 's) and thus effects can be considered small, except for life satisfaction and unemployment, for which they can be considered small to medium. 


\section{Table 1}

Multilevel Associations Between First Work Transitions and Self-Esteem and Life Satisfaction

\begin{tabular}{|c|c|c|c|c|c|c|c|c|c|c|c|c|}
\hline \multirow[b]{2}{*}{ Coefficient } & \multicolumn{6}{|c|}{ First Employment $^{1}$} & \multicolumn{6}{|c|}{ First Unemployment ${ }^{2}$} \\
\hline & $b$ & $99.9 \% \mathrm{CI}$ & $p$ & $b$ & $99.9 \% \mathrm{CI}$ & $p$ & $b$ & $99.9 \% \mathrm{CI}$ & $p$ & $b$ & $99.9 \% \mathrm{CI}$ & $p$ \\
\hline Intercept & -.02 & $(-.07, .03)$ & .238 & -.10 & $(-.15,-.05)$ & $<.001$ & .12 & $(.08, .15)$ & $<.001$ & .01 & $(-.03, .04)$ & .508 \\
\hline Testing & $-.02 *$ & $(-.02,-.01)$ & $<.001$ & $-.01 *$ & $(-.01,-.01)$ & $<.001$ & $-.01 *$ & $(-.02,-.01)$ & $<.001$ & $-.00 *$ & $(-.01,-.00)$ & $<.001$ \\
\hline Quadratic age & $-.04 *$ & $(-.06,-.02)$ & $<.001$ & .01 & $(-.01, .02)$ & .068 & $-.07 *$ & $(-.08,-.05)$ & $<.001$ & $-.01 *$ & $(-.03, .00)$ & .005 \\
\hline Selection & $.19 *$ & $(.13, .25)$ & $<.001$ & $.12 *$ & $(.06, .17)$ & $<.001$ & $-.16^{*}$ & $(-.26,-.05)$ & $<.001$ & $-.32 *$ & $(-.41,-.22)$ & $<.001$ \\
\hline Anticipation & .00 & $(-.08, .07)$ & .894 & -.04 & $(-.11, .03)$ & .045 & $-.10 *$ & $(-.20,-.01)$ & $<.001$ & $-.16^{*}$ & $(-.25,-.07)$ & $<.001$ \\
\hline
\end{tabular}

Note. $p=$ raw $p$ value obtained from the analyses that is not yet adjusted for multiple testing. $*$ significant after correction for false discovery rate.

Significant effects for time coefficients in bold. 
Next, we explored whether self-esteem and life satisfaction predicted the experience of repeated work transitions. We first computed residualized scores that partialed out gender, age, and testing effects. To omit assessments that might have been affected by anticipatory effects, we computed the (between-group standardized) mean across assessments that occurred at least two years before the first unemployment. We compared participants who had one, two, or three transitions of each event. Because we ran four regressions, we applied an alpha level of .05/4 $=.01$. No comparison remained statistically significant after this correction. We therefore concluded that selection effects did not differ between repetitions. Socialization Effects of First Work Transitions on Self-esteem and Life Satisfaction

Next, we investigated the effects of the first employment and unemployment that occurred in the study period (see Table 1). The testing effects were statistically significant and negative in all models, indicating a decrease in self-esteem and life satisfaction with every additional assessment. However, testing effects were very small (self-esteem: $b=-.02 /-$ .01 ; life satisfaction: $b=-.01 / .00$ ), which corresponds to an annual change of 0 to $-.02 S D$ units. Women reported lower self-esteem $(b=-.14 /-.15)$ but higher life satisfaction $(b=$ .05/.04). The gender effects resemble effect sizes (Cohen's $d$ ) and can be considered small. Age effects were small, too (although note that coefficients cannot be interpreted as effect sizes). Linear age was positively associated with self-esteem $(b=.05 / .04)$ and life satisfaction $(b=.02 / .01)$, corresponding to a change of .01 to $.05 S D$ units across 5 years. Quadratic age was negatively associated with self-esteem $(b=-.04 /-.07)$. Further inspection indicated a gradual flattening of the increase after midlife.

Consistent with Hypothesis 2.1, we found a negative anticipatory effect of unemployment on self-esteem and life satisfaction. Participants decreased in self-esteem $(b=$ $-.10)$ and life satisfaction $(b=-.16)$ before the beginning of unemployment. In other words, the effect would translate into an accumulated decrease of between .10 and $.16 S D$ units if the 
last measurement took place 5 years before the event (note that pre-event measurements often took place later, e.g., 2 years before the event, in which case the predicted accumulated decreased would be a fraction of this). However, we did not find average socialization effects that started after unemployment (neither sudden nor lasting changes). Inconsistent with Hypothesis 2.2, participants did, on average, neither change in self-esteem or life satisfaction before nor after the beginning of employment.

The self-esteem and life satisfaction trajectories for employment are depicted in Panel A and Panel B of Figure 1 and those for unemployment in Panel A and Panel B of Figure 2, respectively (see supplemental content $\mathrm{S} 13$ for a description of the visualization). The figures and a comparison of the time coefficients before (preLin) and after unemployment (postYear plus postBase) show that after the anticipatory drop before unemployment, there was no full recovery to baseline levels.

To estimate individual variability, we modeled random effects around the time coefficients in the models above. We ran four analyses for each combination of transition and outcome variable (e.g., unemployment and self-esteem). In each analysis, we included a random slope around one time coefficient (e.g., the postYear coefficient) and investigated whether this resulted in a significant improvement in fit, compared to the original model (which contained only random intercepts). This was true for all comparisons, indicating that there was substantial individual variability in all effects of unemployment and employment on both self-esteem and life satisfaction, $p \mathrm{~s} \leq .00002$. 


\section{Figure 1}

Self-esteem and Life Satisfaction Before and After the First Employment Transition

\section{A. Self-esteem}

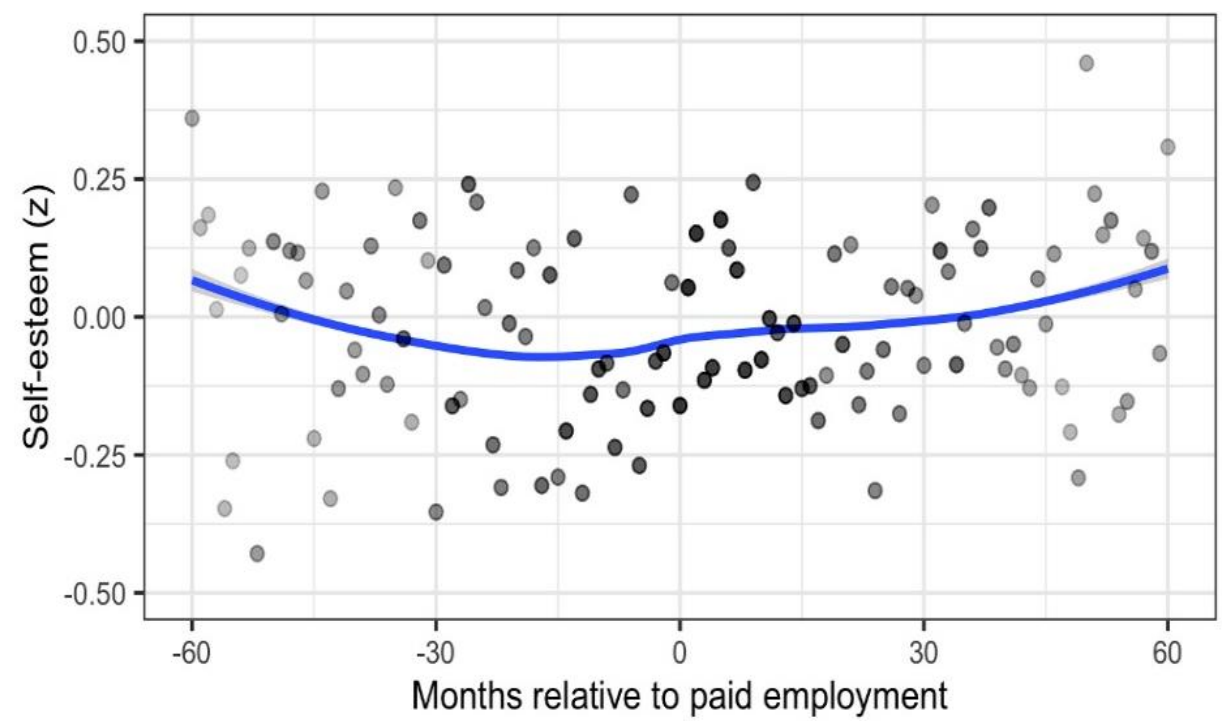

B. Life Satisfaction

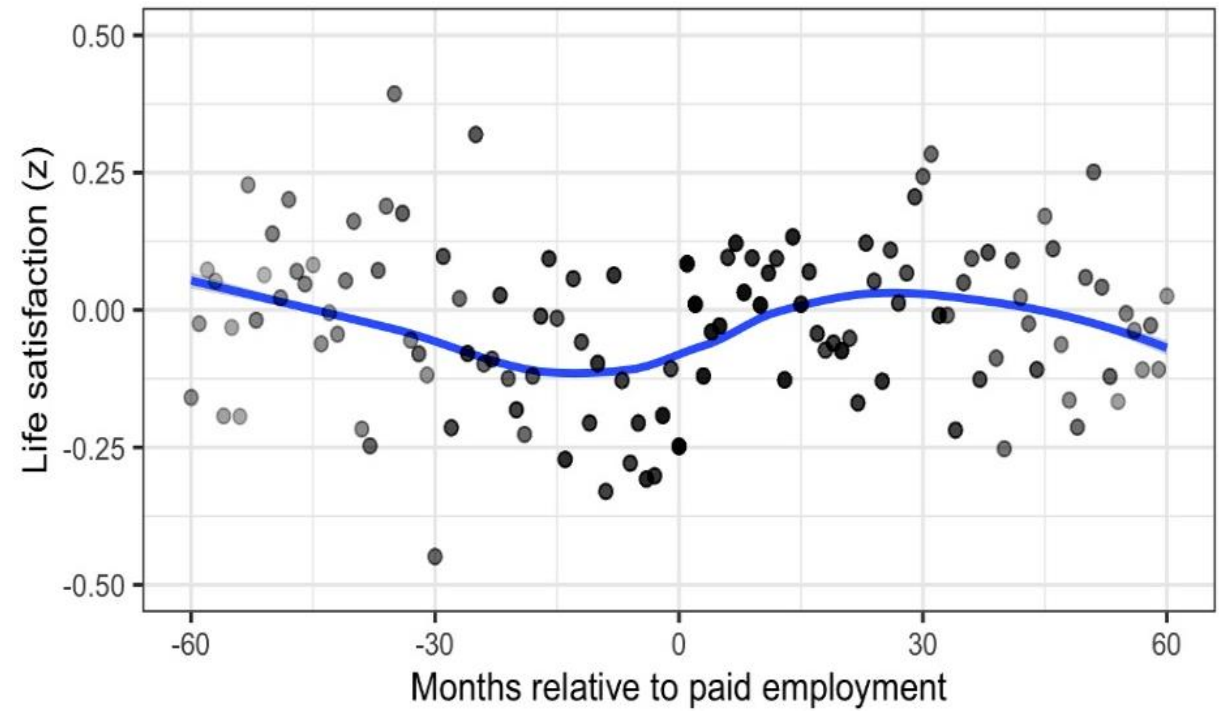

Note. Figure depicting standardized and residualized (controlling for gender, age, and testing effects) self-esteem and life satisfaction values as a function of the number of months relative to the first employment transition of participants who experienced the transition into employment during the study period. The graph was created from average (across participants) outcome variables' levels during every month before, during, and after the transition for which there was at least one assessment available. 


\section{Figure 2}

Self-esteem and Life Satisfaction Before and After the First Unemployment Transition

A. Self-esteem

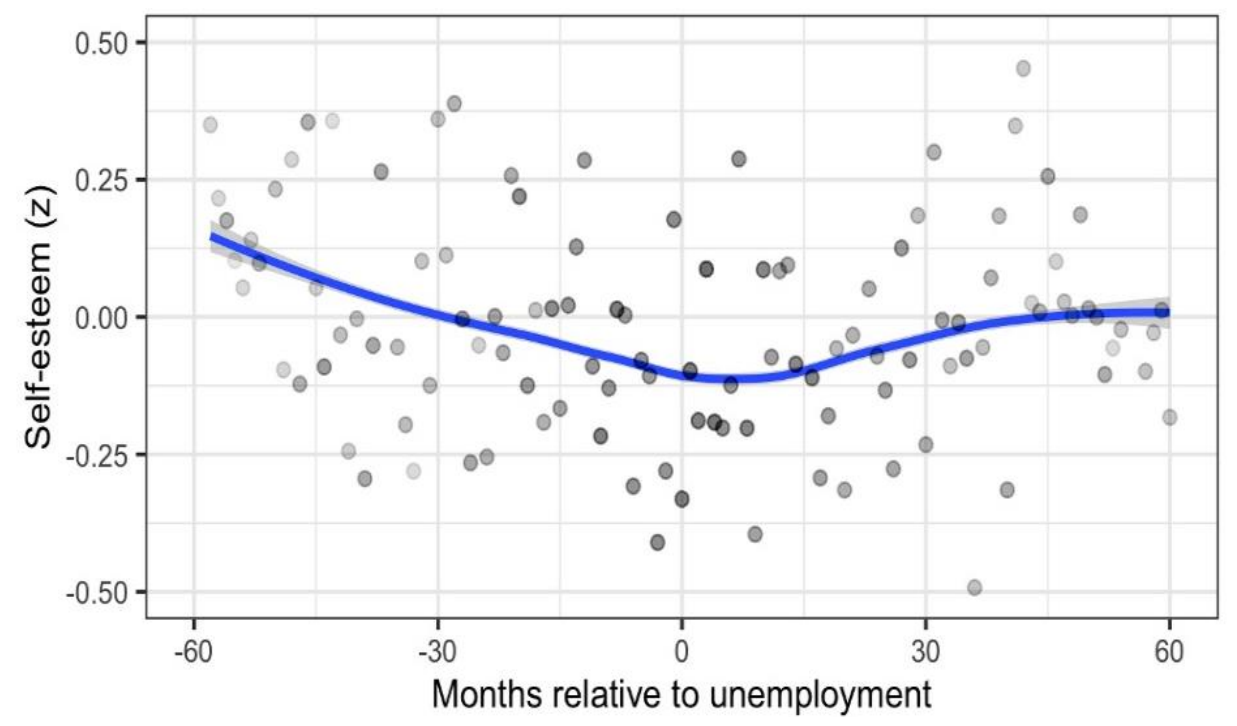

B. Life Satisfaction

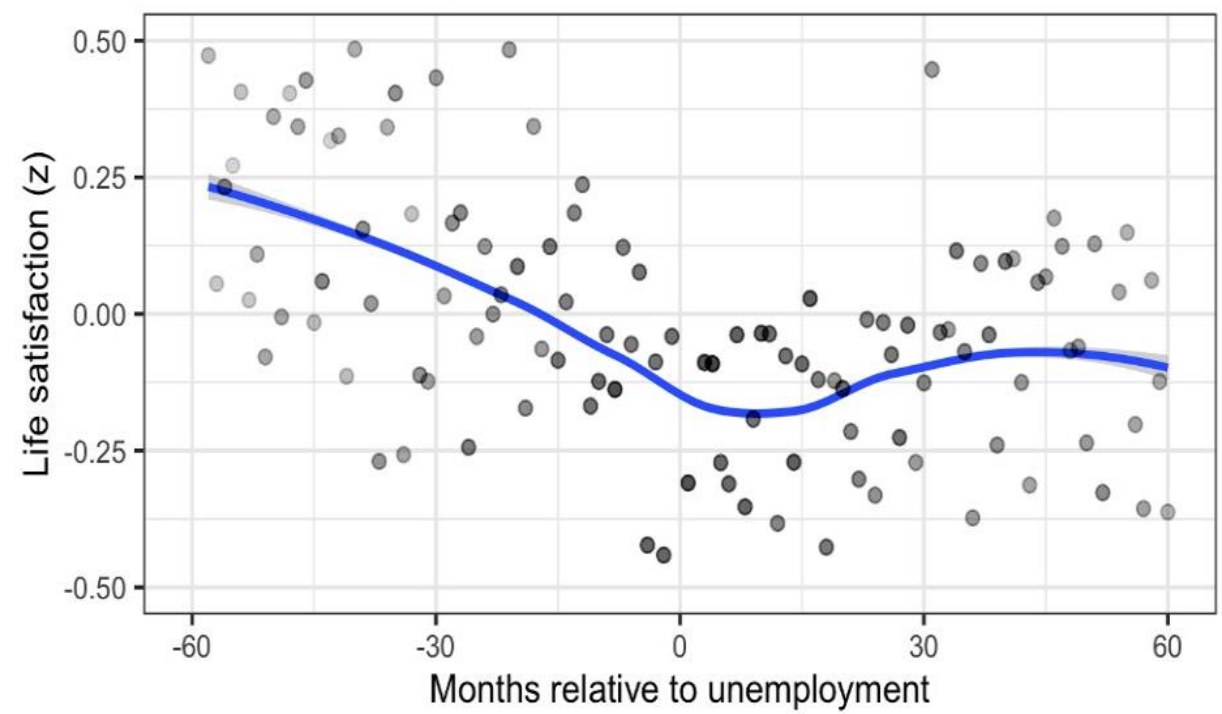

Note. Figure depicting standardized and residualized (controlling for gender, age, and testing effects) self-esteem and life satisfaction values as a function of the number of months relative to the first unemployment transition of participants who experienced the transition into unemployment during the study period. The graph was created from average (across participants) outcome variables' levels during every month before, during, and after the transition for which there was at least one assessment available. 


\section{Combined Effects of Employment and Unemployment Transitions}

In addition to analyzing employment and unemployment transitions separately, we analyzed them in one model as described in the analytic strategy section (i.e., we estimated effects for transitions independent from the previous transition). As shown in Table 2, results from the analyses of combined transitions mostly replicated the results of the separate unemployment and employment transitions, indicating that the negative anticipatory effect found for unemployment transitions was independent of employment transitions. One additional finding was that a very small positive post-event baseline effect of employment on life satisfaction appeared $(b=.05)$ when unemployment transitions were accounted for.

\section{The Effects of Repeated Work Transitions}

To test the effects of repeated transitions, we ran the model described in the analytic strategy section. Results indicated that none of the time coefficient $\mathrm{x}$ repetition interaction effects were statistically significant: No $p$-value was smaller than .05 , and after correcting for false discovery rate, all $p$-values equaled 1 . These results indicate that the employment and unemployment transitions did not show robust associations with different levels of selfesteem and life satisfaction if they occurred repeatedly.

To illustrate the effects of repeated work transitions, we modeled the effect of two repetitions of the employment and unemployment transitions on self-esteem and life satisfaction in multivariate regressions (i.e., both the first and second transition were included, and hence, their effects were accounted for one another). The regression analyses indicated that there was a negative anticipatory effect of unemployment and that people showed a small boost after starting reemployment in addition to regressing towards the mean. 
Table 2

Combined Effects of First Employment and Unemployment Transitions

\begin{tabular}{|c|c|c|c|c|c|c|}
\hline \multirow[b]{2}{*}{ Coefficient } & \multicolumn{3}{|c|}{ Self-esteem } & \multicolumn{3}{|c|}{ Life satisfaction } \\
\hline & $b$ & $99.9 \% \mathrm{CI}$ & $p$ & $b$ & $99.9 \% \mathrm{CI}$ & $p$ \\
\hline Intercept & -.01 & $(-.06, .04)$ & .528 & -.09 & $(-.13,-.04)$ & $<.001$ \\
\hline Testing & $-.02 *$ & $(-.02,-.01)$ & $<.001$ & $-.01 *$ & $(-.01,-.00)$ & $<.001$ \\
\hline Female gender & $-.14 *$ & $(-.19,-.10)$ & $<.001$ & $.05 *$ & $(.01, .09)$ & $<.001$ \\
\hline Linear age & $.05 *$ & $(.04, .06)$ & $<.001$ & $.02 *$ & $(.01, .03)$ & $<.001$ \\
\hline Quadratic age & $-.04 *$ & $(-.06,-.03)$ & $<.001$ & .01 & $(-.01, .02)$ & .266 \\
\hline \multicolumn{7}{|l|}{ Employment } \\
\hline - Selection & $.20 *$ & $(.14, .26)$ & $<.001$ & $.14 *$ & $(.09, .20)$ & $<.001$ \\
\hline - Anticipation & .00 & $(-.08, .08)$ & .968 & -.03 & $(-.10, .04)$ & .207 \\
\hline - Post-event year & .03 & $(-.06, .11)$ & .319 & .01 & $(-.06, .08)$ & .606 \\
\hline - Post-event baseline & .00 & $(-.08, .08)$ & .876 & $.05 *$ & $(-.01, .12)$ & .008 \\
\hline - Post-event linear & .04 & $(-.05, .12)$ & .151 & .02 & $(-.05, .09)$ & .395 \\
\hline \multicolumn{7}{|l|}{ Unemployment } \\
\hline - Selection & $-.20 *$ & $(-.30,-.09)$ & $<.001$ & $-.35 *$ & $(-.45,-.26)$ & $<.001$ \\
\hline - Anticipation & $-.09 *$ & $(-.19, .02)$ & .005 & $-.14 *$ & $(-.23,-.05)$ & $<.001$ \\
\hline - Post-event year & -.02 & $(-.13, .10)$ & .613 & -.06 & $(-.15, .04)$ & .045 \\
\hline - Post-event baseline & .00 & $(-.11, .11)$ & .985 & -.05 & $(-.14, .04)$ & .078 \\
\hline - Post-event linear & .00 & $(-.11, .10)$ & .890 & .03 & $(-.06, .12)$ & .259 \\
\hline
\end{tabular}

Note. $p=$ raw $p$ value obtained from the analyses that is not yet adjusted for multiple testing. * significant after correction for false discovery rate. Significant effects for time coefficients in bold. 
To illustrate the effects, we computed predicted values for employment and unemployment transitions that were two years apart and smoothed the output with the "loess" algorithm in ggplot2 (with a span of .4, established after some trial-and-error). As can be seen in Figure 3, the repeated transitions had similar effects; effects were generally more pronounced for life satisfaction than for self-esteem. If shorter intervals (events every 6-12 months) were chosen, participants would not recover from the decline of unemployment before the next employment, resulting in a general downward trend.

\section{Figure 3}

Predicted Self-esteem and Life Satisfaction Scores for Repeated Work Transitions

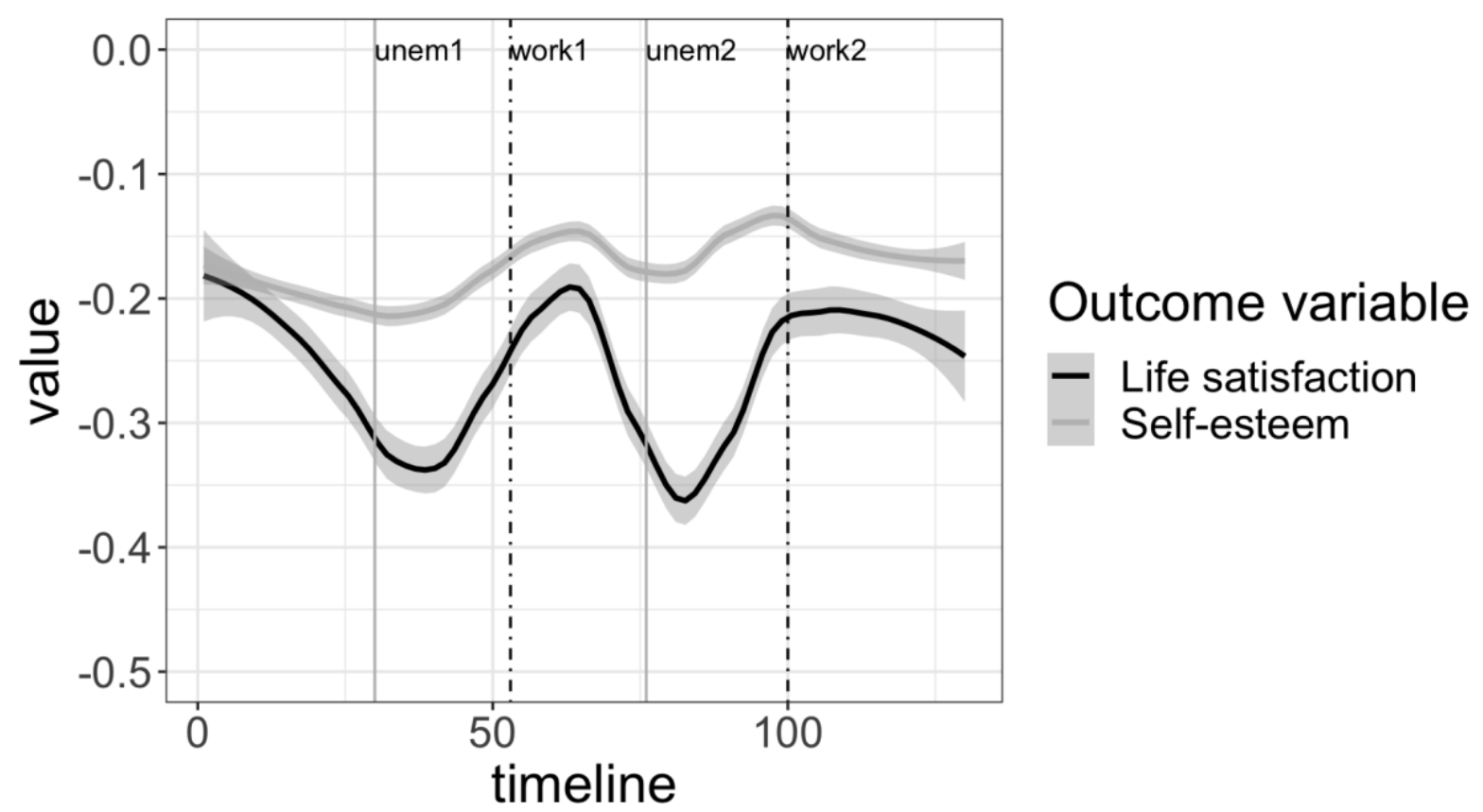

Note. Predicted self-esteem and life satisfaction scores for repeated unemployment and employment transitions across two-year intervals between the various events. The grey solid lines indicate the unemployment events and the black dotted lines the employment events. Note that values were slightly below zero because of the negative selection effect. 


\section{Event-Related Characteristics as Moderators of Socialization Effects}

Next, we ran moderator analyses while adjusting the $p$ values to account for multiple testing, as described above and in the R scripts. For job satisfaction, we found several moderator effects for employment in support of Hypotheses 3.1 and 3.2, but not for unemployment. Job satisfaction moderated the effect of the employment transition on both self-esteem and life satisfaction (see Figure 4 and Table 3): High job satisfaction predicted a baseline increase in self-esteem $(b=.08)$ and life satisfaction $(b=.09)$. For self-esteem this effect did not remain significant after accounting for multiple testing. In addition, the postYear $\mathrm{x}$ job satisfaction effect indicated a sudden short-term decline when subsequent job satisfaction was high $(b=-.09)$, which effectively delayed the positive baseline shift by a year. The interactions between job satisfaction and the post-event linear effects (i.e., all changes in $S D$ units from 0 to 5 years after the event beyond short-term and baseline change) were negative for both self-esteem $(b=-.08)$ and life satisfaction $(b=-.08)$.

Together, these findings indicate a non-linear trajectory for the high job satisfaction group, as some of the post-employment time interaction coefficients were positive and some negative (e.g., self-esteem: $b=-.09 / .08 /$-.08 for post-event year / post-event baseline / postevent linear, respectively; for an illustration, see Figure 4; note that effects were small). Specifically, those who started a satisfying job increased in self-esteem and life satisfaction in the year after (which was not or less so the case for those who started a less satisfying job), followed by a gradual decrease thereafter. However, levels did not fully return to baseline and were higher 5 years after the employment than before and higher than the levels of those with low job satisfaction. 


\section{Figure 4}

Job Satisfaction as Moderator of the Effect of Employment

A: Self-Esteem

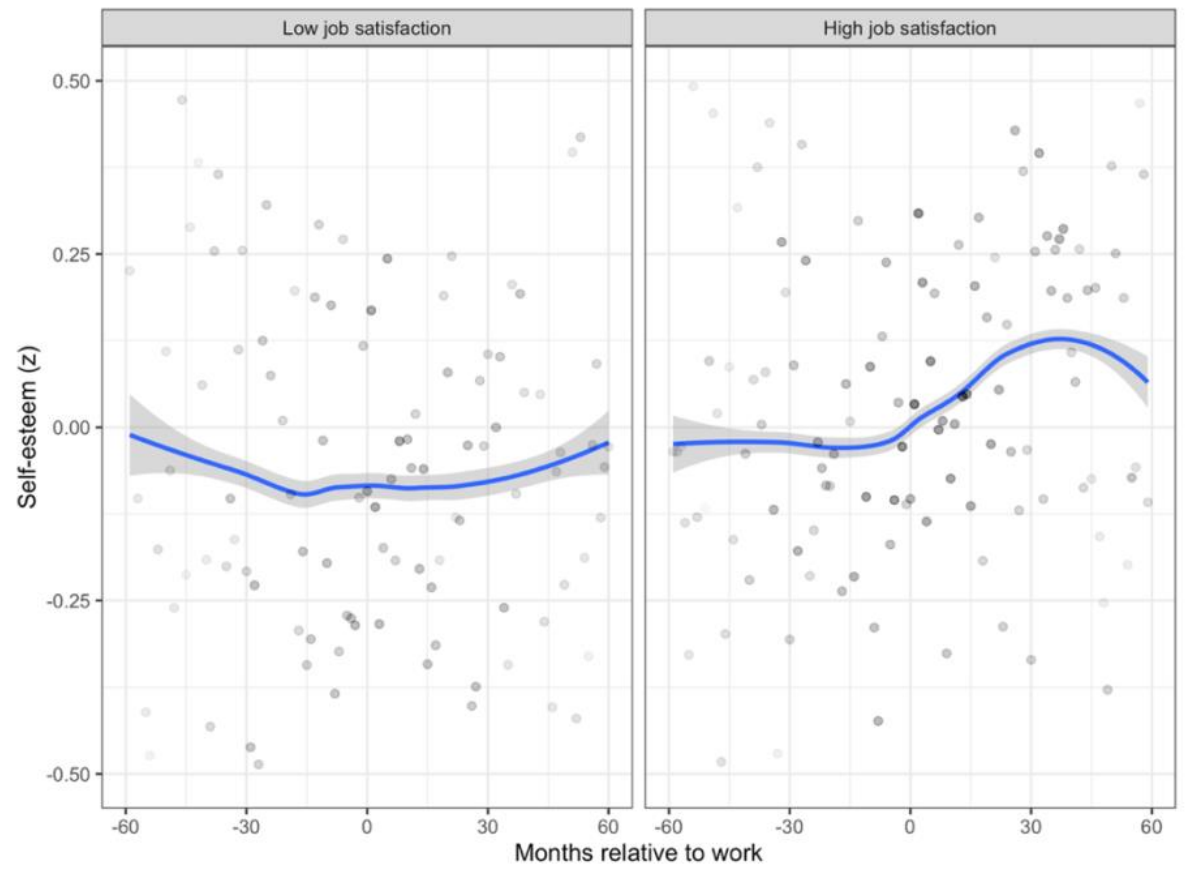

B. Life satisfaction

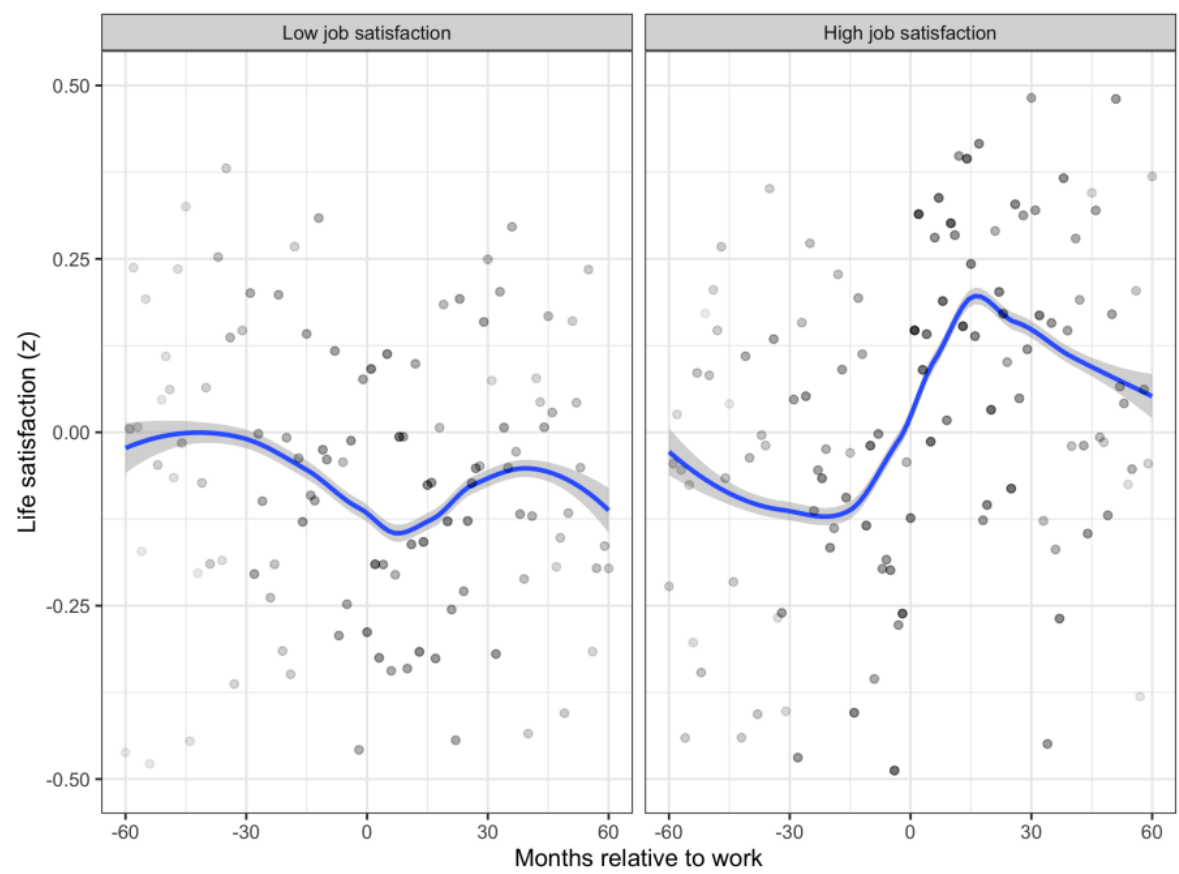

Note. On the y-axis, standardized and residualized (controlling for gender, age, and testing) levels of self-esteem and life satisfaction are depicted. 


\section{Table 3}

Moderator Effects of Job Satisfaction on the Association on the Effect of Work Transitions on Self-Esteem and Life Satisfaction

\begin{tabular}{|c|c|c|c|c|c|c|c|c|c|c|c|c|}
\hline & \multicolumn{6}{|c|}{ Employment } & \multicolumn{6}{|c|}{ Unemployment } \\
\hline & \multicolumn{2}{|c|}{ Self-esteem } & \multicolumn{3}{|c|}{ Life satisfaction } & & \multicolumn{4}{|c|}{ Self-esteem } & \multicolumn{2}{|c|}{ Life satisfaction } \\
\hline & $b$ & $99.9 \% \mathrm{CI}$ & $p$ & $b$ & $99.9 \% \mathrm{CI}$ & & $b$ & $99.9 \% \mathrm{CI}$ & $p$ & $b$ & $99.9 \% \mathrm{CI}$ & $p$ \\
\hline Intercept & -.14 & $(-.46, .19)$ & .411 & -.58 & $(-.88,-.29)$ & $<.001$ & .02 & $(-.19, .24)$ & .841 & -.29 & $(-.50,-.07)$ & .009 \\
\hline Testing & -.00 & $(-.02, .01)$ & .825 & -.00 & $(-.02, .01)$ & .512 & -.01 & $(-.03, .01)$ & .389 & -.02 & $(-.04, .00)$ & .056 \\
\hline Female gender & -.10 & $(-.20,-.00)$ & .046 & .11 & $(.03, .20)$ & .012 & -.12 & $(-.25, .00)$ & .051 & .16 & $(.04, .28)$ & .010 \\
\hline Linear age & .03 & $(.01, .06)$ & .019 & $-.05^{*}$ & $(-.07,-.02)$ & $<.001$ & $.09 *$ & $(.06, .13)$ & $<.001$ & .04 & $(.01, .08)$ & .004 \\
\hline Quadratic age & -.05 & $(-.09,-.01)$ & .021 & -.03 & $(-.07, .00)$ & .070 & .05 & $(-.01, .11)$ & .087 & $.11 *$ & $(.05, .16)$ & $<.001$ \\
\hline Job Satisfaction & $.19^{*}$ & $(.13, .24)$ & $<.001$ & $.26^{*}$ & $(.20, .31)$ & $<.001$ & $.26^{*}$ & $(.19, .33)$ & $<.001$ & $.39 *$ & $(.32, .46)$ & $<.001$ \\
\hline Selection & .09 & $(-.23, .41)$ & .579 & .33 & $(.03, .62)$ & .030 & -.02 & $(-.24, .21)$ & .888 & .10 & $(-.12, .32)$ & .362 \\
\hline Anticipation & $-.15^{*}$ & $(-.24,-.06)$ & .001 & -.09 & $(-.17,-.01)$ & .025 & -.13 & $(-.23,-.03)$ & .009 & -.09 & $(-.18, .00)$ & .062 \\
\hline Post-event year & .01 & $(-.06, .07)$ & .829 & .01 & $(-.04, .06)$ & .625 & -.01 & $(-.10, .08)$ & .803 & -.04 & $(-.11, .04)$ & .335 \\
\hline Post-event baseline & .09 & $(.03, .15)$ & .006 & $.11 *$ & $(.06, .16)$ & $<.001$ & -.01 & $(-.09, .07)$ & .790 & -.07 & $(-.13, .00)$ & .057 \\
\hline Post-event linear & -.05 & $(-.14, .03)$ & .234 & .04 & $(-.03, .11)$ & .300 & -.08 & $(-.18, .03)$ & .162 & .06 & $(-.04, .15)$ & .228 \\
\hline Job Sat. x Anticipation & .04 & $(-.02, .10)$ & .205 & .06 & $(.01, .12)$ & .020 & -.01 & $(-.08, .07)$ & .819 & .09 & $(.02, .16)$ & .015 \\
\hline Job Sat. x PostYear & $-.09 *$ & $(-.16,-.03)$ & .003 & .01 & $(-.04, .05)$ & .825 & .03 & $(-.06, .12)$ & .473 & -.04 & $(-.11, .03)$ & .288 \\
\hline Job Sat. x PostBase & .08 & $(.02, .14)$ & .007 & $.09 *$ & $(.04, .14)$ & $<.001$ & .04 & $(-.04, .12)$ & .370 & .01 & $(-.06, .08)$ & .820 \\
\hline Job Sat. x PostLin & $-.08 *$ & $(-.13,-.03)$ & .001 & $-.08^{*}$ & $(-.12,-.03)$ & $<.001$ & -.08 & $(-.15,-.02)$ & .016 & -.08 & $(-.14,-.03)$ & .004 \\
\hline
\end{tabular}

Note. $p=$ raw $p$ value obtained from the analyses that is not yet adjusted for multiple testing. $*$ significant after correction for false discovery rate.

Significant moderator effects in bold. 
We found a moderator effect for unemployment duration for self-esteem but not for life satisfaction (see Figure 5 and Table 4): Participants who experienced longer spells of unemployment displayed a larger anticipatory decrease in their self-esteem $(b=-.09)$, followed by a larger linear increase (recovery) after the event $(b=.09)$. These moderator effects indicate changes in $S D$ units across 5 years. Those with longer spells of unemployment had still lower levels in self-esteem than those with shorter spells six years after. Hypothesis 3.3 was thus partly supported.

\section{Figure 5}

Unemployment Duration as Moderator of the Effect of Unemployment

\section{A. Self-Esteem}

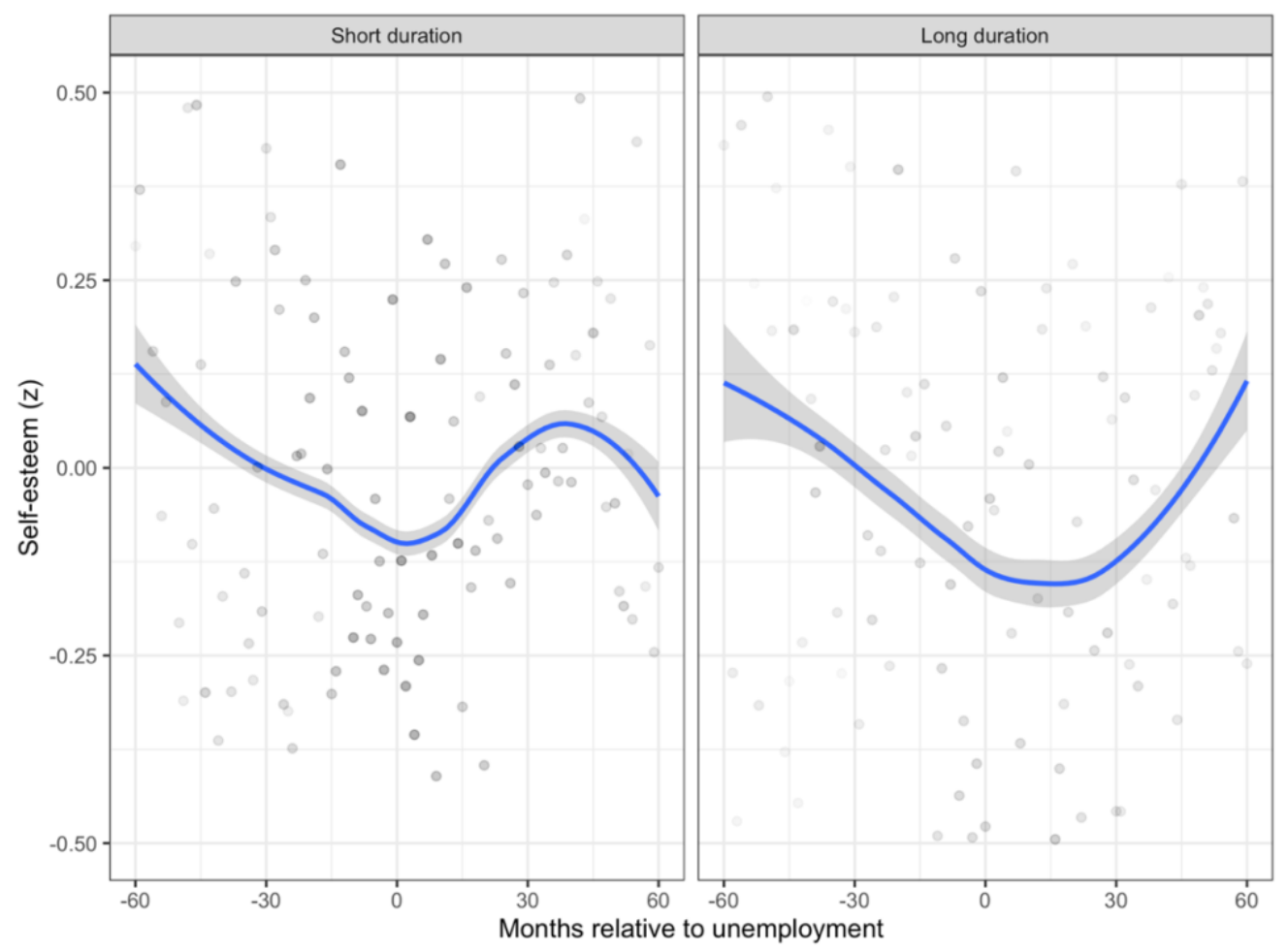


B. Life Satisfaction

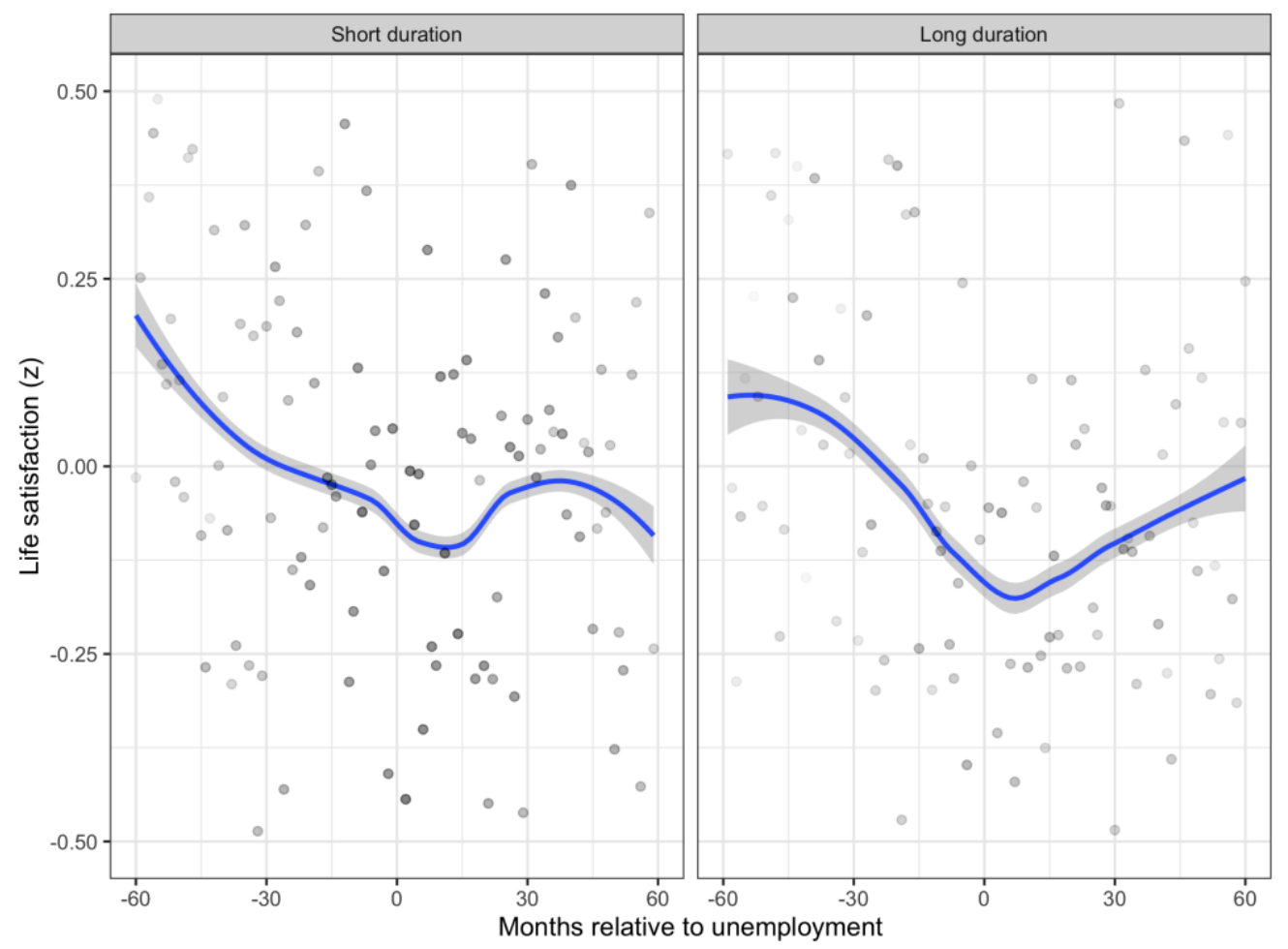

Note. On the y-axis, standardized and residualized (controlling for gender, age, and testing) levels of self-esteem and life satisfaction are depicted. 


\section{Table 4}

Moderator Effects of Unemployment Duration on the Effect of Unemployment on Self-Esteem and Life Satisfaction

\begin{tabular}{|c|c|c|c|c|c|c|}
\hline & \multicolumn{3}{|c|}{ Self-esteem } & \multicolumn{3}{|c|}{ Life satisfaction } \\
\hline & $b$ & $99.9 \% \mathrm{CI}$ & $p$ & $b$ & $99.9 \% \mathrm{CI}$ & $p$ \\
\hline Intercept & .11 & $(-.18, .40)$ & .452 & -.23 & $(-.53, .07)$ & .131 \\
\hline Testing & -.01 & $(-.03, .01)$ & .269 & -.01 & $(-.03, .01)$ & .267 \\
\hline Female gender & -.10 & $(-.22, .02)$ & .118 & $.22 *$ & $(.09, .34)$ & .001 \\
\hline Job Satisfaction & $.13 *$ & $(.10, .16)$ & $<.001$ & $.07 *$ & $(.04, .10)$ & $<.001$ \\
\hline Linear age & .04 & $(-.02, .09)$ & .187 & $.08^{*}$ & $(.03, .13)$ & .002 \\
\hline Quadratic age & -.07 & $(-.14,-.00)$ & .043 & -.04 & $(-.21, .12)$ & .602 \\
\hline Selection & -.10 & $(-.40, .19)$ & .488 & -.03 & $(-.33, .26)$ & .830 \\
\hline Anticipation & $-.20 *$ & $(-.30,-.10)$ & $<.001$ & $-.18 *$ & $(-.28,-.09)$ & $<.001$ \\
\hline Post-event year & -.03 & $(-.11, .04)$ & .381 & -.07 & $(-.14,-.01)$ & .029 \\
\hline Post-event baseline & .02 & $(-.05, .10)$ & .541 & -.01 & $(-.07, .05)$ & .718 \\
\hline Post-event linear & -.09 & $(-.19, .01)$ & .064 & -.01 & $(-.10, .08)$ & .878 \\
\hline Job Satisfaction x Anticipation & $-.09 *$ & $(-.15,-.03)$ & .003 & -.05 & $(-.18, .09)$ & .497 \\
\hline Job Satisfaction x Post-event year & .06 & $(-.00, .13)$ & .058 & -.01 & $(-.14, .13)$ & .898 \\
\hline Job Satisfaction x Post-event baseline & -.03 & $(-.09, .03)$ & .366 & -.08 & $(-.21, .05)$ & .228 \\
\hline Job Satisfaction x Post-event linear & $.09 *$ & $(.04, .14)$ & .001 & .15 & $(.04, .26)$ & .006 \\
\hline
\end{tabular}

Note. $p=$ raw $p$ value obtained from the analyses that is not yet adjusted for multiple testing. * significant after correction for false discovery rate. Significant moderator effects in bold.

\section{Personal Characteristics as Moderators and Covariates}

Tables S14 and S15 of the supplementary materials show the separate moderation analyses for the demographic variables. In all models, age, education, income, and occupational prestige had positive main effects on self-esteem and life satisfaction. Female gender had a positive main effect on life satisfaction but a negative main effect on selfesteem. None of the interaction effects of the demographic variables and the time coefficients on self-esteem and life satisfaction were significant after correcting for the false discovery rate. 
In exploratory analyses that were requested in review, we examined whether the effects between work transitions and self-esteem and life satisfaction held after accounting for the Big Five traits. With one exception (see below), all previously significant effects remained significant and all previously non-significant effects remained non-significant. The time coefficients in the model without the Big Five traits (see Table 1) changed from those in the model with the Big Five traits (see Table 5) as follows: For selection, effect sizes decreased by half (change in estimates before / after accounting for the Big Five traits: employment and self-esteem: $b=.19 / .08$; employment and life satisfaction; $b=.12 / .06$; unemployment and self-esteem: $b=-.16 /-.08$ ), except for unemployment and life satisfaction, for which the effect size remained similar $(b=-.32 /-.27)$.

For anticipation, the effect sizes remained virtually identical (average / range of absolute change: $b=.02 / b=.01$ and $b=.02$ ), except for unemployment and self-esteem, for which the effect decreased from $b=-.10$ to $b=-.05$ and no longer met our adjusted threshold for significance $(p=.03)$. The effect sizes of the post-event time coefficients remained virtually identical (the average / range of absolute change for post-event year: $b=.01 / b=0$ and $b=.02$; post-event baseline: $b=.03 / b=.02$ and $b=.04$; and post-event linear: $b=.01 /$ $b=.00$ and $b=.01)$.

Together, accounting for the Big Five traits resulted in a decrease in the unemployment models resulted in a decrease (by approximately half) of the selection and anticipatory effects for self-esteem, but not for life satisfaction (the decrease was negligible). Accounting for the Big Five traits in the employment models resulted in attenuation, but not disappearance, of selection effects for both self-esteem and life satisfaction. 


\section{Table 5}

Multilevel Associations Between First Work Transitions and Self-Esteem and Life Satisfaction While Accounting for the Big Five Traits

\begin{tabular}{|c|c|c|c|c|c|c|c|c|c|c|c|c|}
\hline \multirow[b]{3}{*}{ Coefficient } & \multicolumn{6}{|c|}{ First Employment } & \multicolumn{6}{|c|}{ First Unemployment } \\
\hline & \multicolumn{3}{|c|}{ Self-esteem } & \multicolumn{3}{|c|}{ Life Satisfaction } & \multicolumn{3}{|c|}{ Self-esteem } & \multicolumn{3}{|c|}{ Life Satisfaction } \\
\hline & $b$ & $99.9 \% \mathrm{CI}$ & $p$ & $b$ & $99.9 \% \mathrm{CI}$ & $p$ & $b$ & $99.9 \% \mathrm{CI}$ & $p$ & $b$ & $99.9 \% \mathrm{CI}$ & $p$ \\
\hline Intercept & .03 & $(-.01, .07)$ & .01 & -.08 & $(-.13,-.04)$ & $<.001$ & .09 & $(.07, .12)$ & $<.001$ & -.01 & $(-.05, .02)$ & .17 \\
\hline Testing & $-.02 *$ & $(-.02,-.01)$ & $<.001$ & $-.01 *$ & $(-.02,-.01)$ & $<.001$ & $-.02 *$ & $(-.02,-.01)$ & $<.001$ & $-.01 *$ & $(-.01,-.00)$ & $<.001$ \\
\hline Female gender & $-.05 *$ & $(-.09,-.01)$ & $<.001$ & $.13 *$ & $(.09, .17)$ & $<.001$ & $-.06 *$ & $(-.09,-.02)$ & $<.001$ & $.13^{*}$ & $(.09, .17)$ & $<.001$ \\
\hline Linear age & $.03 *$ & $(.02, .03)$ & $<.001$ & .00 & $(-.00, .01)$ & .10 & $.02 *$ & $(.02, .03)$ & $<.001$ & .00 & $(-.01, .01)$ & .49 \\
\hline Quadratic age & $-.03 *$ & $(-.04,-.01)$ & $<.001$ & $.03 *$ & $(.01, .04)$ & $<.001$ & $-.04 *$ & $(-.05,-.03)$ & $<.001$ & $.01 *$ & $(.00, .03)$ & .00 \\
\hline Selection & $.08 *$ & $(.04, .13)$ & $<.001$ & $.06 *$ & $(.01, .11)$ & $<.001$ & $-.08 *$ & $(-.16,-.00)$ & $<.001$ & $-.27 *$ & $(-.36,-.18)$ & $<.001$ \\
\hline Anticipation & -.01 & $(-.07, .05)$ & .60 & -.02 & $(-.09, .05)$ & .27 & -.05 & $(-.14, .03)$ & .03 & $-.14 *$ & $(-.24,-.05)$ & $<.001$ \\
\hline Post-event year & .02 & $(-.05, .09)$ & .34 & .02 & $(-.07, .10)$ & .53 & -.01 & $(-.11, .09)$ & .82 & -.05 & $(-.16, .07)$ & .18 \\
\hline Post-event baseline & -.05 & $(-.12, .01)$ & .01 & -.02 & $(-.09, .06)$ & .42 & -.03 & $(-.12, .07)$ & .37 & -.04 & $(-.15, .07)$ & .23 \\
\hline Post-event linear & .02 & $(-.04, .08)$ & .28 & .02 & $(-.06, .09)$ & .46 & .02 & $(-.07, .10)$ & .48 & .04 & $(-.05, .14)$ & .13 \\
\hline
\end{tabular}

Note. $p=$ raw $p$ value obtained from the analyses that is not yet adjusted for multiple testing. * significant after correction for false discovery rate.

Significant effects for time coefficients in bold. 


\section{Additional Robustness Testing}

We reran exploratory analyses that were requested in review using propensity-score matched comparison groups ${ }^{2}$. We found that effects were generally comparable: all previously significant effects remained significant and had a similar magnitude (see Table S16 of the supplementary materials). However, some previously non-significant findings were significant: we found negative anticipatory effects of employment for self-esteem $(b=-$ $.12)$ and life satisfaction $(b=-.08)$ that were, however, partly compensated after a year after the transition ( $b=.08, b=.05$, respectively, the latter was however non-significant).

\section{Discussion}

The present study investigated the association between work transitions (employment and unemployment) and psychological adjustment (self-esteem and life satisfaction) using prospective multi-wave data from a large, nationally representative sample from the Netherlands. Our first aim was to examine the bidirectional links between work transitions and self-esteem and life satisfaction over time. We found evidence for bidirectional effects. First, high levels of self-esteem and life satisfaction predicted the occurrence of employment and low levels predicted the occurrence of unemployment, indicating selection effects. Second, both self-esteem and life satisfaction decreased in anticipation of unemployment, indicating anticipatory effects, but remained, on average, relatively stable during the employment transition. The effects of the first versus repeated work transitions did not differ.

Our second aim was to examine whether two event-related characteristics of work transitions contributed to individual differences in change in self-esteem and life satisfaction. Job satisfaction moderated the effect of employment on life satisfaction and the duration of unemployment moderated the effect of unemployment on self-esteem. We found no evidence for moderating effects of any of the demographic variables. Results were mostly robust when accounting for the Big Five traits and using propensity score matching. 


\section{Self-Esteem and Life Satisfaction Predicted Employment and Unemployment}

The finding that people who scored higher on life satisfaction were less likely to experience unemployment and more likely to experience employment replicates previous studies (Clark, 2003; Graham et al., 2004; Luhmann \& Eid, 2009). Our findings provide novel evidence that these selection effects generalize to self-esteem, which extends previous research by using large power, accounting for personal characteristics, testing effects, and false discovery rates (e.g., Huysse-Gaytandjieva et al., 2015; Salmela-Aro \& Nurmi, 2007). Together, these findings emphasize that individuals play an active role in shaping their work lives and, hence, their development, as proposed by transactional and lifespan perspectives.

There are at least two mechanisms that may drive these effects and should be examined in future research. First, people with higher self-esteem and life satisfaction may have been more successful at obtaining a job. They showed higher levels of job search behavior (Kanfer, Wanberg, \& Kantrowitz, 2001) and better interview performance (Liden, Martin, \& Parsons, 1993), possibly because of (overly) positive perceptions of their competence (Dufner, Reitz, \& Zander, 2015) and likability (Reitz, Motti-Stefanidi, \& Asendorpf, 2016). Second, lower self-esteem and life satisfaction, which are associated with reduced work performance (Judge \& Bono, 2001), may have led to getting fired (Wagenaar, Kompier, Houtman, van den Bossche, \& Taris, 2015).

\section{Self-Esteem and Life Satisfaction Decreased in Anticipation of Unemployment}

The finding that self-esteem and life satisfaction decreased before the onset of unemployment provides novel evidence for anticipatory effects. These anticipatory effects seem to have had a long-term impact. Despite some rebound effects, even 5 years after experiencing unemployment, both self-esteem and life satisfaction levels did not fully recover to baseline levels. Our findings extend previous research that focused mostly on reaction and adaptation to unemployment or pointed to anticipatory effects but did, unlike our 
study, not test their robustness (e.g., Luhmann et al., 2012; McKee-Ryan et al., 2005; Paul \& Moser, 2009). Due to the analytical approach of the present study, the anticipatory effects are distinct from (unbiased by) selection effects and post-event change. In addition, anticipatory effects of unemployment remained significant when accounting for employment, indicating that the estimates are robust and unbiased by interfering effects of employment transitions. Moreover, the fact that findings were largely replicated when using a matched comparison group provides additional confidence in the robustness of our findings.

Our finding supports the notion that people experience psychological changes prior important work transitions, possibly as they anticipate the event (Lucas et al., 2004; Luhmann et al., 2013). Anticipatory change has been discussed for other stressful life events: Divorce is often preceded by a period of conflict and separation (e.g., Bleidorn, Schwaba, Denissen, \& Hopwood, 2021; van Scheppingen \& Leopold, 2020) and widowhood is often preceded by a period of spousal illness (e.g., Infurna et al., 2017). Similarly, it is plausible that people often know in advance whether and when they might get laid off. Recessions, company problems, and personal conflicts or performance issues may foreshadow potential lay-offs (Wagenaar et al., 2015). We did, however, not directly test whether people were really consciously aware of their upcoming unemployment. We can therefore not exclude the possibility that there are also other reasons for the pre-event declines, such as temporary changes in the circumstances due to which people actively initiate work transitions. However, given that we found preevent declines in this sample from the Netherlands, a country with stringent notification procedures that inform employees about lay-offs early on (OECD, 2019), points into the direction of anticipatory effects, even if they operate in parallel with other mechanisms.

The finding that the anticipatory change before unemployment generalizes to selfesteem is novel. It is in line with the notion that self-esteem falls in response to failures in relevant life domains (Crocker \& Wolfe, 2001; James, 1890). More specifically, it supports 
the hypothesis that experiences that inform about a person's successes and failures in the work domain are a source of self-esteem (Wojciszke et al., 2011). Furthermore, it seems that change prior to work transitions is not limited to health and well-being but also applies to self-evaluations, which informs the discussion of possible mechanisms. Identity change might be a mechanism, which is considered to change in anticipation of major life events (e.g., Pasupathi, Mansour, \& Brubaker, 2007). Given that work is a crucial aspect of one's identity (e.g., Wille \& De Fruyt, 2014), it might be that people start to rewrite their life story once they know that unemployment is imminent, with consequences for self-esteem.

The sudden and long-term post-unemployment increases were not significant after correction and could not compensate for the pre-transition decline. Although self-esteem and life satisfaction reached the lowest points within the first year after the unemployment transition (at around 10 and 6 months, respectively), our findings suggest that they are mostly the result of a rapid decrease before instead of after the transition. Previous studies have, however, reported change after the unemployment transition (for a meta-analysis, see Luhmann et al., 2012). A reason for the divergent findings might be that most previous studies did not account for anticipatory effects, testing effects, and selection effects when examining reaction and adaptation effects, unlike our study. Previous approaches might thus have led to biased estimates of post-event change because the pre-event levels tend to diverge from their habitual level (see Luhmann et al., 2012). Results from a study that overcame these methodological challenges reported, in line with our findings, that most Big Five trait changes occurred before life events (Denissen et al., 2019). Retirement is another type of work transition that can be anticipated, yet it is normative (in contrast to unemployment). For retirement, changes in self-esteem were predominantly found before the event, too (Schwaba $\&$ Bleidorn, 2018). Together, these studies suggest that shared mechanisms might be at work for different life events that lead to changes that predominantly occur before the event. 
More knowledge about anticipatory change may help advance theory development as it provides new clues for where to look for mechanisms that explain life transition changes. The evidence for anticipatory change implies that we might look beyond environmental processes triggered by the new context to psychological processes triggered when expecting the event. A possible explanation for the larger pre- versus post-unemployment change is that people might become anxious about the upcoming unemployment and job search, which might abate after the event (Kramer et al., 2021). The soon-to-be unemployed might overestimate the intensity and duration of their emotional reactions (Wilson \& Gilbert, 2005). Another potential explanation is that, as people approach unemployment, they might already experience stressors such as the looming financial strain, which might first result in a decrease in psychological adjustment. However, these pre-event stressors might also trigger compensation strategies, such as cutting down expenses, as part of a proactive, behavioral optimizing process that might prevent additional drops once unemployment starts (Baltes \& Dickson, 2001; Heckhausen, Wrosch, \& Schulz, 2010).

\section{No Consistent Change Patterns Linked to Employment}

We found no evidence for change in self-esteem and life satisfaction before and after starting employment in the main analyses. However, we found two effects in the additional analyses that extend previous research: First, when simultaneously accounting for unemployment, employment predicted a small increase in life satisfaction after a year (and not within the first year). As we found no such effect when examining employment separately, this finding suggests that unemployment transitions (that possibly occurred after a year past the employment) might have interfered with its positive effects (i.e., attenuated them slightly). Future research is needed to examine such potential interference effects further. Second, when using a matched comparison group, we found negative anticipatory effects for employment that were, however, partly compensated a year after the transition. 
Together, these findings suggest that the experience of employment might not be as positive as expected. Our finding complements previous studies that found only small effects of the first job on self-esteem change (Reitz et al., 2020) and no effects of reemployment on life satisfaction (Luhmann et al., 2012). Our finding indicates that the absence of a general boost in self-esteem and life satisfaction might be a general phenomenon after employment. A plausible explanation is a hedonic adaptation process (Diener et al. 2006): Newly employed people might experience a brief increase in their life satisfaction but gradually return to their original levels. Instead of average effects, we found significant individual differences in psychological adjustment to employment, which is in line with what was found for the first job after university (Reitz et al., 2020) and underlines the need to attend more strongly to individual variability in change.

Together, we found more consistent effects for unemployment than for employment. This pattern of results is in line with suggestions that negative events have a greater and longer lasting impact than positive events (Baumeister, Bratslavsky, Finkenauer, \& Vohs, 2001; for an overview, see Larsen \& Prizmic, 2008). Our study provides evidence that this general principle might also apply to work transitions. A possible explanation for this pattern might be differences in societal expectations regarding the two transitions. Joining the labor force and maintaining a job is a normative (i.e., societally expected) developmental task in adulthood (Hutteman, Hennecke, Orth, Reitz, \& Specht, 2014). Being employed per se is, thus, nothing extraordinary and might therefore not lead to a boost in self-esteem and life satisfaction. However, being unemployed could be seen as a failure of fulfilling a socially expected role, which might explain the declines in self-esteem and life satisfaction. The idea that the normativity of occupational statuses shapes their impact on self-esteem and life satisfaction corresponds to one's recent study's finding that unemployment had a less negative effect on health when unemployment rates were high (Heggebø \& Elstad, 2018). 


\section{No Selection Nor Socialization Effects for Repeated Work Transitions}

We found that people with lower levels of self-esteem and life satisfaction were as likely to experience a second or third employment and unemployment transition as they were to experience a first transition (i.e., selection). This finding provides novel evidence suggesting that while people with low levels of self-esteem and life satisfaction are at risk to experience unemployment in general, there is no enhanced risk to experience a second or third spell. Their greater likelihood to experience any spell, however, of course does make them more likely to experience repeated spells in an additive fashion.

In addition, we found that work transitions had similar effects on self-esteem and life satisfaction (i.e., socialization) when experienced repeatedly: the magnitude of the decline in self-esteem and life satisfaction was the same at each unemployment spell. Together, these findings neither support sensitization (or habituation) models that predict a less intense decline with each new unemployment experience nor stress-sensitization or -accumulation models that predict a more intense decline. Instead, the degree of work-transition induced change in self-esteem and life satisfaction seems to be independent from whether the transition has already been experienced or not. Previous research also found the magnitude of the decline in life satisfaction to be comparable with each unemployment spell but found the levels to decrease more and more with each spell (Booker \& Sacker, 2011; Luhmann \& Eid, 2009). A reason why we did not find sensitization patterns might be that we used stricter statistical controls (when omitting these controls, we found differences between one and two spells). Another reason might be that the unemployment spells in our Dutch study were shorter than the ones in the German SOEP, which might point to sensitization patterns only occurring after longer unemployment phases.

\section{People Differed Considerably in Their Change During Work Transitions}


Our findings demonstrate considerable interindividual differences in the change of self-esteem and life satisfaction during work transitions, which is in line with previous research (Doré \& Bolger, 2018; Lucas, 2007; Reitz et al., 2020). The finding that the random slopes of all time coefficients were significant adds to the literature that the rates of anticipatory, short-term, baseline change, and post-transition change showed substantial heterogeneity. The results of the moderator analyses support the notion that event-related characteristics of work transitions contribute to this heterogeneity (Eid \& Larsen, 2008). Job Satisfaction Moderated Work Transition Effects on Self-esteem and Life Satisfaction

We found that job satisfaction moderated the effects of employment on self-esteem and life satisfaction. More specifically, people with low job satisfaction showed more stability after the employment transition, whereas people with high job satisfaction initially increased in psychological adjustment (which was only significant for life satisfaction) although this boost dissipated somewhat in terms of later declines in self-esteem and life satisfaction. Together with previous findings (Reitz et al., 2020), our findings suggest that the employment transition per se does not have a positive effect on self-esteem and life satisfaction due to the variability in job satisfaction: only some jobs are satisfying and provide sources for self-esteem and life satisfaction. The findings call for a refinement of the notion that employment is good for people's psychological adjustment: self-esteem and life satisfaction only seem to increase when people start a satisfying job (see also Crocker \& Wolfe, 2001; Hogan \& Roberts, 2004; James, 1890).

Our findings provide additional weight to the call for paying closer attention to the specific event characteristics to better understand individual differences in transition-induced change (see also Luhmann et al., 2020). An important event characteristic that may explain why job satisfaction moderated employment effects is job success, as people who are satisfied with their jobs are more likely to be successful in their jobs (Judge \& Bono, 2001) 
and job success in daily life was found to covary with self-esteem change across the transition to work (Reitz et al., 2020). It might be that self-esteem only started to increase after some time during the transition to a satisfying job because indicators of success such as positive feedback or promotions might occur only after having worked in a new job for some time. The notion of contingent self-esteem might also help explain the upward trend in selfesteem for those satisfied with their jobs: if a new job provides opportunities for success (and hence, job satisfaction; see Judge \& Bono, 2001), people might increasingly base their selfesteem on this job, which in turn leads to increases in self-esteem (Crocker \& Wolfe, 2001).

Life satisfaction increased among those starting a satisfying job and it peaked around 15 months into the new job. A potential explanation is a sudden availability of resources that fulfill basic needs (Ryan \& Deci, 2000). The satisfaction of basic psychological needs at work is linked with job satisfaction and life satisfaction (for a meta-analysis, see Van den Broeck et al., 2016). Need satisfaction has also been considered to explain the effect of job satisfaction on life satisfaction (Unanue, Gomez, Cortez, Oyanedel, \& Mendiburo-Seguel, 2017). Some of the need-fulfilling resources might have long-term effects, given that we found that the life satisfaction levels declined were still higher for people with satisfying jobs 5 years after the employment transition. Levels did, however, decrease after about 15 months, which might point to a certain degree of hedonic adaptation (Diener et al. 2006).

\section{Unemployment Duration Moderated Effects on Self-esteem but not Life Satisfaction}

Participants who experienced longer periods of unemployment displayed a larger decrease before and a larger increase after the unemployment transition. While these effects were visible for both outcomes, they were only significant for self-esteem. This finding is novel, as previous research has neither examined unemployment duration as moderator of self-esteem change nor of anticipatory change in general. This finding provides a new perspective on the role of unemployment duration. A prominent explanation for the greater 
decline in psychological adjustment for people who experienced longer unemployment durations are cumulative stress processes (Warr et al., 1982). Our findings add that this more pronounced decline might occur already prior to unemployment and can therefore not be due to the post-unemployment stressors. It may be that people anticipate the duration of their unemployment. That might be the case for people for whom job opportunities are rare, such as those working in niche sectors. For them, unemployment might be more threatening than for others, and hence, unemployment might impact their self-esteem more strongly before it starts.

After the unemployment transition, participants with longer durations rebounded to some degree, but not fully, from the anticipatory drop. This finding corresponds to the idea that people can adapt somewhat to unemployment as they find ways to deal with the stressors after some time (Clark, 2006). One potential coping mechanism that deserves more attention is psychological disengagement, which is considered as a defense strategy for stigmatized individuals (Major, Spencer, Schmader, Wolfe, \& Crocker, 1998). Unemployed workers are stigmatized and seen as less competent (Norlander, Ho, Shih, Walters, \& Pittinsky, 2020). Complementary to the idea that people might increasingly base their self-esteem on work if it is satisfactory, people might increasingly detach their self-esteem from the work domain after long periods of unemployment as a means of self-protection and to maintain their self-esteem levels. Such defense strategies might not be at play during short periods of unemployment, because there is no need for self-protection if a new job might already be around the corner.

Taken together, our findings suggest both similarities and differences in the environmental antecedents of self-esteem and life satisfaction. Both were negatively predicted by unemployment but not predicted by employment, which suggests a shared functioning in responding to these environmental experiences. At the same time, the moderator effects differed, which suggests a certain degree of distinctness in their 
antecedents. An important avenue for future research is to further study their shared and distinct environmental and biological antecedents to define the boundaries of these constructs and to understand their differential functioning in relation to environmental experiences.

\section{Personal Characteristics as Moderators and Covariates}

We found that the main effects held after accounting for age, gender, SES, and the Big Five personality traits (with one exception). In addition, we found no evidence for moderating effects of age, gender, and SES. If solely stable mechanisms would have been at work, there would not have been effects above and beyond the demographic and personality covariates. These findings suggest that the observed effects are robust across demographic groups and individuals with different personality traits and thus, provide additional confidence that our results indicate selection and socialization effects.

Still, three selection effects and one anticipatory effect were attenuated when personality traits were included as covariates ( 3 out of the 4 attenuated effects were for selfesteem). These are novel findings that point to potentially shared mechanisms of effects in life satisfaction and personality, and in particular, in self-esteem and personality, which might be due to the shared identity-related processes discussed above. Future research is needed to further examine the role of the Big Five traits in associations between work transitions and self-esteem and life satisfaction.

\section{Limitations and Future Directions}

The present study has several strengths that overcome multiple constraints of previous research. We used a large, representative sample, a 11-year prospective longitudinal design, and multiple, rather fine-grained repeated assessments. We applied advanced analyses with strict controls to examine trajectories before and after work transitions with high precision, bidirectional associations, combined and repeated transitions, event-related and demographic moderator variables, and demographic characteristics and the Big Five traits as covariates. 
Nevertheless, the study has several limitations that are informative for future research. Our results pointed to two event-related sources of the heterogeneity in self-esteem and life satisfaction changes following work transitions (i.e., job satisfaction and unemployment duration), but other sources remain to be explored. The psychological, idiosyncratic experience of life transitions that was also shown to shape effects of other life transitions (e.g., bereavement; Reitz et al., 2022) deserves more attention. Studies using quasiexperimental designs that target specific work transitions (e.g., following a cohort into employment or employees of a company that goes bankrupt) are needed as they can better capture peoples' experiences and individual circumstances than national panel studies. Such studies should directly test whether the work transitions were anticipated.

Future research should also capture the reasons for work transitions. Following selfdetermination theory (Ryan \& Deci, 2000), it might be that when motivation for employment is intrinsic (e.g., people expect it to be very fulfilling) as opposed to extrinsic (e.g., social pressure) people increase in their self-esteem and life satisfaction. Similarly, it might be that when unemployment is voluntary as opposed to being laid off, people adjust better (Kassenboehmer \& Haisken-DeNew, 2008). Following social investment theory, the importance of work for the individual, especially the centrality of the role to the individuals' identity, is considered to be a promising moderator (Lodi-Smith \& Roberts, 2007; though see Den Boer et al., 2019). Narratives that capture the centrality of work in people's identity might illuminate key change mechanisms.

While our study used more frequent and dense assessments than most research, it was not suited to capture fast-paced change in thoughts, feelings, and behaviors and link them to monthly or yearly change in self-esteem and life satisfaction (e.g., Wrzus \& Roberts, 2017). Intensive longitudinal designs that include repeated phases of daily diary or experience sampling methods are needed but rarely used in studies on the psychological adaptation to 
life transitions (Hektner, Schmidt, \& Csikszentmihalyi, 2007). Such designs should be tailored to work transitions to provide insights into the change mechanisms (e.g., daily success and failure experiences at work or in the job search process; Reitz et al., 2020).

Although the data may be generalized to the Dutch population due to the representativeness of the sample, the effects might be different in other countries. The anticipatory effect of unemployment might be more pronounced in the Netherlands, where employees tend to see it coming early on, than in countries with weaker pre-termination resolution mechanisms. The Netherlands has the strictest procedures for dismissals in the OECD countries $(4,17$ on a $0-6$ scale indicating stringent notification procedures; OECD, 2019). In contrast, the US and Canada (both 0,69) have the least stringent procedures, as the employer does not have to provide a reason to the worker before dismissal. Germany, where the SOEP is from that was used in many studies on this topic, is in the middle field $(1,67)$.

The absence of an additional drop once unemployment starts might also not replicate in countries with less regulatory protection. The Netherlands has relatively high severance pay (1,33 months of pay after notice versus 0 months in Germany and the US; maximum: 4 months in Turkey) and relatively high unemployment benefits (75\% of last pay during the first 2 months) that are paid for long durations (48\% after 5 years; US: 18\%; Germany: 23\%) even in the case of resignation (OECD, 2020). Future research should replicate our study in different countries and occupational groups with varying degrees of employment protection. In addition, attempts should be made to account for cultural contexts that shape the value of work and hence, may influence the reactions to unemployment (Schwartz, 1999).

Finally, while life satisfaction and self-esteem are important indicators of healthy functioning, they are not exhaustive indicators of well-being. Different trajectories after work transitions may be found for more direct indicators of personal growth and eudaimonic wellbeing (Infurna \& Luthar, 2016; Jayawickreme, Blackie, Forgeard, Roepke, \& Tsukayama, 
2021). Furthermore, future research should extend this research to work transitions that were not covered here, including promotions and retirement.

\section{Conclusion}

The present study examined the reciprocal effects between work transitions and selfesteem and life satisfaction. Consistent with transactional perspectives, our results suggest that the experience of work transitions and self-esteem and life satisfaction are linked via dynamic, bidirectional transactions. That is, self-esteem and life satisfaction predisposed people to experience work transitions: people with high levels of self-esteem and life satisfaction were more likely to become employed and less likely to become unemployed. In addition, work transitions had effects on self-esteem and life satisfaction, but the effects occurred mostly pre-transition: the average person decreased in self-esteem and life satisfaction before unemployment started, which had long-term effects that people did not fully recover from six years after; yet they did not show additional drops after unemployed started. The effect of unemployment was similar if experienced repeatedly. We found considerable individual variability in self-esteem and life satisfaction, which was related to event-related characteristics of the work transitions. Specifically, people who were satisfied with their new job showed increases in life satisfaction. People who experienced longer periods of unemployment displayed a larger anticipatory decrease in their self-esteem.

The present study has important implications for research and practice. The study underscores the importance of rigorous, well-timed longitudinal designs to capture the transition-adjustment dynamics, the specific change trajectories before and after work transitions, and the individual differences in psychological adjustment to work transitions. The study identified a group at risk: People with low self-esteem and low life satisfaction seem to be more likely to become unemployed and less likely to reenter the labor market, which decreases their self-esteem and life satisfaction further. Especially if these events are 
long and frequent, negative effects on their psychological adjustment might accumulate.

Furthermore, we cautiously conclude that programs should start long before unemployment begins and aim at preventing long unemployment spells. 


\section{References}

Anglim, J., Horwood, S., Smillie, L. D., Marrero, R. J., \& Wood, J. K. (2020). Predicting psychological and subjective well-being from personality: A metaanalysis. Psychological Bulletin, 146(4), 279-323. https://doi.org/10.1037/bul0000226

Baird, B. M., Lucas, R. E., \& Donnellan, M. B. (2010). Life satisfaction across the lifespan: Findings from two nationally representative panel studies. Social Indicators Research, 99(2), 183-203. https://doi.org/10.1007/s11205-010-9584-9

Baltes, B. B. \& Dickson, M. W. (2001) Using life-span models in industrial-organizational psychology: The theory of selective optimization with compensation. Applied Developmental Science, 5(1), 51-62. https://doi.org/10.1207/S1532480XADS0501_5

Baltes, P. B., Lindenberger, U., \& Staudinger, U. M. (2006). Life span theory in developmental psychology. In W. Damon, \& R. M. Lerner (Eds.), Theoretical models of human development (pp. 569-664). New York: Wiley.

Bates, D., Maechler, M., Bolker, B., \& Walker, S. (2014). lme4: Linear mixed-effects models using 'Eigen' and S4 (R package Version 1.0-6) [Computer software]. Retrieved from http://CRAN.R-project.org/package=lme4

Baumeister, R. F., Bratslavsky, E., Finkenauer, C., \& Vohs, K. D. (2001). Bad is stronger than good. Review of General Psychology, 5(4), 323-370. doi:10.1037//10892680.5.4.323.

Bleidorn, W., Hopwood, C. J., \& Lucas, R. E. (2018). Life events and personality trait change. Journal of Personality, 86(1), 83-96. https://doi.org/10.1111/jopy.12286

Bleidorn, W., \& Schwaba, T. (2018). Retirement is associated with change in selfesteem. Psychology and Aging, 33(4), 586. https://doi.org/10.1037/pag0000253

Bleidorn, W., Schwaba, T., Denissen, J. J. A., \& Hopwood, C. J. (2021). Charting self-esteem during marital dissolution. Journal of Personality, 98, 9-22. https://doi- 
org.tilburguniversity.idm.oclc.org/10.1111/jopy.12525

Blustein, D. L. (2008). The role of work in psychological health and well-being: A conceptual, historical, and public policy perspective. American Psychologist, 63(4), 228-240. https://doi.org/10.1037/0003-066X.63.4.228

Booker, C. L., \& Sacker, A. (2012). Psychological well-being and reactions to multiple unemployment events: Adaptation or sensitisation? Journal of Epidemiology and Community Health, 66(9), 832-838. https://doi.org/10.1136/jech.2010.126755

Bowling, N. A., Eschleman, K. J., \& Wang, Q. (2010). A meta-analytic examination of the relationship between job satisfaction and subjective well-being. Journal of Occupational and Organizational Psychology, 83(4), 915-934. https://doi.org/10.1348/096317909X478557

Caspi, A., Bem, D. J., \& Elder, G. H. (1989). Continuities and consequences of interactional styles across the life course. Journal of Personality, 57(2), 375-406. https://doi.org/10.1111/j.1467-6494.1989.tb00487.x

Cetre, S., Clark, A. E., \& Senik, C. (2016). Happy people have children: Choice and selfselection into parenthood. European Journal of Population, 32(3), 445-473. https://doi.org/10.1007/s10680-016-9389-x

Clark, A. E. (2003). Unemployment as a social norm: Psychological evidence from panel data. Journal of Labor Economics, 21(2), 323-351. https://doi.org/10.1086/345560

Clark, A.E. (2006). A note on unhappiness and unemployment duration. Applied Economics Quarterly, 52(4), 291-308. http://ftp.iza.org/dp2406.pdf

Clark, A. E., Diener, E., Georgellis, Y., \& Lucas, R. E. (2008). Lags and leads in life satisfaction: A test of the baseline hypothesis. Economic Journal, 118(529), 222-243. https://doi.org/10.1111/j.1468-0297.2008.02150.x

Clark, A. E., Flèche, S., \& Senik, C. (2016). Economic growth evens out happiness: Evidence 
from six surveys. Review of Income and Wealth, 62(3), 405-419.

https://doi.org/10.1111/roiw.12190

Clark, A. E., Georgellis, Y., \& Sanfey, P. (2001). Scarring: The psychological impact of past unemployment. Economica, 68(270), 221-241. https://doi.org/10.1111/14680335.00243

Crocker, J., \& Wolfe, C. T. (2001). Contingencies of self-worth. Psychological Review, 108(3), 593-623. https://doi.org/10.1037/0033-295X.108.3.593

den Boer, L., Klimstra, T. A., Branje, S. J. T., Meeus, W. H. T., \& Denissen, J. J. A. (2019).

Personality maturation during the transition to working life: Association with commitment as possible indicator of social investment. European Journal of Personality, 33(4), 456-467.

Denissen, J. J. A., Luhmann, M., Chung, J. M., \& Bleidorn, W. (2019). Transactions between life events and personality traits across the adult lifespan. Journal of Personality and Social Psychology, 116(4), 612-633. https://doi.org/10.1037/pspp0000196

Diener, E. D., Emmons, R. A., Larsen, R. J., \& Griffin, S. (1985). The satisfaction with life scale. Journal of Personality Assessment, 49(1), 71-75. https://doi.org/10.1207/s15327752jpa4901_13

Diener E. (2009). Subjective well-being. In: E. Diener (Ed), The science of well-being (pp. 11-58). Amsterdam: Springer. https://doi.org/10.1007/978-90-481-2350-6

Diener, E., Lucas, R. E., \& Scollon, C. N. (2006). Beyond the hedonic treadmill: Revising the adaptation theory of well-being. American Psychologist, 61(4), 305-314. https://doi.org/10.1037/0003-066X.61.4.305

Donnellan, B. M., Kenny, D. A., Trzesniewski, K. H., Lucas, R. E., \& Conger, R. D. (2012). Using trait-state models to evaluate the longitudinal consistency of global self-esteem from adolescence to adulthood. Journal of Research in Personality, 46(6), 634-645. 
https://doi.org/10.1016/j.jrp.2012.07.005

Doré, B., \& Bolger, N. (2018). Population- and individual-level changes in life satisfaction surrounding major life stressors. Social Psychological and Personality Science, 9(7), 875-884. https://doi.org/10.1177/1948550617727589

Dufner, M., Reitz, A. K., \& Zander, L. (2015). Antecedents, consequences, and mechanisms: On the longitudinal interplay between academic self-enhancement and psychological adjustment. Journal of Personality, 83(5), 511-522. https://doi.org/10.1111/jopy.12128

Eid, M., \& Diener, E. (2004). Global judgments of subjective well-being: Situational variability and long-term stability. Social Indicators Research, 65(3), 245-277. https://doi.org/10.1023/b:soci.0000003801.89195.bc

Eid, M., \& Larsen, R. J. (Eds.). (2008). The science of subjective well-being. New York: Guilford Press.

Elder, G. H. (1998). The life course as developmental theory. Child Development, 69(1), 112. https://doi.org/10.1111/j.1467-8624.1998.tb06128.x

Flint, E., Bartley, M., Shelton, N., \& Sacker, A. (2013). Do labour market status transitions predict changes in psychological well-being? Journal of Epidemiology and Community Health, 67(9), 796-802. https://doi.org/10.1136/jech-2013-202425

Ford, M. T., Cerasoli, C. P., Higgins, J. A., \& Decesare, A. L. (2011). Relationships between psychological, physical, and behavioural health and work performance: A review and meta-analysis. Work \& Stress, 25(3), 185-204. https://doi.org/10.1080/02678373.2011.609035

Fraley, R. C., \& Roberts, B. W. (2005). Patterns of continuity: A dynamic model for conceptualizing the stability of individual differences in psychological constructs across the life course. Psychological Review, 112(1), 60-74. https://doi.org/10.1037/0033295X.112.1.60 
Frederick, S., \& Loewenstein, G. (1999). Hedonic adaptation. In D. Kahneman, E. Diener, \& N. Schwarz (Eds.), Well-being: The foundations of hedonic psychology (pp. 302-329). New York: Russell Sage Foundation.

Gebel, M., \& Voßemer, J. (2014). The impact of employment transitions on health in Germany. A difference-in-differences propensity score matching approach. Social Science and Medicine, 108, 128-136. https://doi.org/10.1016/j.socscimed.2014.02.039

Graham, C., Eggers, A., \& Sukhtankar, S. (2004). Does happiness pay? An exploration based on panel data from Russia. Journal of Economic Behavior and Organization, 55(3), 319-342. https://doi.org/10.1016/j.jebo.2003.09.002

Griffeth, R. W., Hom, P. W., \& Gaertner, S. (2000). A meta-analysis of antecedents and correlates of employee turnover: Update, moderator tests, and research implications for the next millennium. Journal of Management, 26(3), 463-488.

https://doi.org/10.1177/014920630002600305

Hahn, E., Specht, J., Gottschling, J., \& Spinath, F. M. (2015). Coping with unemployment: The impact of unemployment duration and personality on trajectories of life satisfaction. European Journal of Personality, 29(6), 635-646. https://doi.org/10.1002/per.2034

Heckhausen, J., Wrosch, C., \& Schulz, R. (2010). A motivational theory of life-span development. Psychological Review, 117(1), 32-60. https://doi.org/10.1037/a0017668

Hektner, J. M., Schmidt, J. A., \& Csikszentmihalyi, M. (2007). Experience sampling method: Measuring the quality of everyday life. Thousand Oaks, CA: Sage.

Heller, D., Judge, T. A., \& Watson, D. (2002). The confounding role of personality and trait affectivity in the relationship between job and life satisfaction. Journal of Organizational Behavior, 23(7), 815-835. https://doi.org/10.1002/job.168

Herber, G. C., Ruijsbroek, A., Koopmanschap, M., Proper, K., Van Der Lucht, F., Boshuizen, H., Polder, J., \& Uiters, E. (2019). Single transitions and persistence of unemployment 
are associated with poor health outcomes. BMC Public Health, 19(1), 1-10. https://doi.org/10.1186/s12889-019-7059-8

Hogan, R., \& Roberts, B. W. (2004). A socioanalytic model of maturity. Journal of Career Assessment, 12(2), 207-217. https://doi.org/10.1177/1069072703255882

CBS (2021) Hoogopgeleid. Retrieved March 22, 2021, from https://www.cbs.nl/nlnl/nieuws/2017/36/meer-hoogopgeleiden-in-alle-beroepsklassen/hoogopgeleid

Hudson, N. W., Lucas, R. E., \& Donnellan, M. B. (2017). Day-to-day affect is surprisingly stable. Social Psychological and Personality Science, 8(1), 45-54. https://doi.org/10.1177/1948550616662129

Hutteman, R., Hennecke, M., Orth, U., Reitz, A. K., \& Specht, J. (2014). Developmental tasks as a framework to study personality development in adulthood and old age. European Journal of Personality, 28, 267-278. https://doi.org/10.1002/per.1959

Huysse-Gaytandjieva, A., Groot, W., Pavlova, M., \& Joling, C. (2015). Low self-esteem predicts future unemployment. Journal of Applied Economics, 18(2), 325-346. https://doi.org/10.1016/S1514-0326(15)30014-3

Infurna, F. J., \& Luthar, S. S. (2016). Resilience to major life stressors is not as common as thought. Perspectives on Psychological Science, 11(2), 175-194. https://doi.org/10.1177/1745691615621271

Infurna, F. J., Wiest, M., Gerstorf, D., Ram, N., Schupp, J., Wagner, G. G., \& Heckhausen, J. (2017). Changes in life satisfaction when losing one's spouse: Individual differences in anticipation, reaction, adaptation and longevity in the German Socio-Economic Panel Study (SOEP). Ageing and Society, 37(5), 899-934.

https://doi.org/10.1017/S0144686X15001543

International Labor Organization (2021). ILO Monitor: COVID-19 and the world of work. https://www.ilo.org/wcmsp5/groups/public/@dgreports/@dcomm/documents/briefingno 
te/wcms_767028.pdf

Jahoda M (1982) Employment and unemployment: A social-psychological analysis.

Cambridge: Cambridge University Press.

Jayawickreme, E., Blackie, L. E., Forgeard, M., Roepke, A. M., \& Tsukayama, E. (2021).

Examining associations between major negative life events, changes in weekly reports

of post-traumatic growth and global reports of eudaimonic well-being. Social

Psychological and Personality Science, https://doi.org/10.1177/19485506211043381

James, W. (1890). The principles of psychology (Vol. 1). New York: Henry Holt.

Judge, T. A., \& Bono, J. E. (2001). Relationship of core self-evaluations traits - self-esteem, generalized self-efficacy, locus of control, and emotional stability - with job satisfaction and job performance: A meta-analysis. Journal of Applied Psychology, 86(1), 80-92. https://doi.org/10.1037/0021-9010.86.1.80

Kanfer, R., Kantrowitz, T. M., \& Wanberg, C. R. (2001). Job search and employment: A personality-motivational analysis and meta-analytic review. Journal of Applied Psychology, 86(5), 837-855. https://doi.org/10.1037/0021-9010.86.5.837

Kinicki, A. J., Prussia, G. E., \& McKee-Ryan, F. M. (2000). A panel study of coping with involuntary job loss. Academy of Management Journal, 43(1), 90-100. https://doi.org/10.5465/1556388

Knoef, M., \& de Vos, K. (2009). The representativeness of LISS, an online probability panel. Retrieved August, 31, 2012.

Kohn, M. L., \& Schooler, C. (1978). The reciprocal effects of the substantive complexity of work and intellectual flexibility: A longitudinal assessment. American Journal of Sociology, 84(1), 24-52. https://doi.org/10.1086/226739

Kramer, A. C., Neubauer, A. B., Leonhardt, A., Dirk, J., Brose, A., \& Schmiedek, F. (2020, August 26). Ambulatory assessment of rumination and worry: Capturing perseverative 
cognitions in children's daily life. https://doi.org/10.31234/osf.io/hgy9b

Krauss, S., \& Orth, U. (2021). Work experiences and self-esteem development: A metaanalysis of longitudinal studies. European Journal of Personality. doi:10.1177/08902070211027142

Kristian Heggebø, \& Elstad, J. I. (2018). Is it easier to be unemployed when the experience is more widely shared? Effects of unemployment on self-rated health in 25 European countries with diverging macroeconomic conditions. European Sociological Review, 34(1), 22-39. https://doi.org/10.1093/esr/jcx080

Kroft, K., Lange, F., Notowidigdo, M. J., \& Katz, L. F. (2016). Long-term unemployment and the great recession: The role of composition, duration dependence, and nonparticipation. Journal of Labor Economics, 34(1), S7-S54. https://doi.org/10.1086/682390

Kuster, F., \& Orth, U. (2013). The long-term stability of self-esteem. Personality and Social Psychology Bulletin, 39(5), 677-690. https://doi.org/10.1177/0146167213480189

Kuster, F., Orth, U., \& Meier, L. L. (2013). High self-esteem prospectively predicts better work conditions and outcomes. Social Psychological and Personality Science, 4(6), 668-675. https://doi.org/10.1177/1948550613479806

Larsen, R. J., \& Prizmic, Z. (2008). Regulation of emotional well-being: Overcoming the hedonic treadmill. In M. Eid \& R. J. Larsen (Eds.), The science of subjective wellbeing (pp. 259-289). New York: Guilford.

Lawson, K. M., \& Robins, R. W. (2021). Sibling constructs: What are they, why do they matter, and how should you handle them? Personality and Social Psychology Review, 10888683211047101

Leary, M. R., \& Baumeister, R. F. (2000). The nature and function of self-esteem: Sociometer theory. In M. P. Zanna (Ed.), Advances in experimental social psychology 
(Vol. 32, pp. 1-62). San Diego, CA: Academic Press.

Liden, R. C., Martin, C. L., \& Parsons, C. K. (1993). ). Interviewer and applicant behavior in employment interviews. Academy of Management Journal, 36(2), 372-386. https://doi.org/10.5465/256527

Lodi-Smith, J., \& Roberts, B. W. (2007). Social investment and personality: A meta-analysis of the relationship of personality traits to investment in work, family, religion, and volunteerism. Personality and Social Psychology Review, 11(1), 68-86. https://doi.org/10.1177/1088868306294590

Lucas, R. E. (2007). Adaptation and the set-point model of subjective well-being: Does happiness change after major life events? Current Directions in Psychological Science, 16(2), 75-79. https://doi.org/10.1111/j.1467-8721.2007.00479.x

Lucas, R. E., \& Donnellan, M. B. (2007). How stable is happiness? Using the STARTS model to estimate the stability of life satisfaction. Journal of Research in Personality, 41(5), 1091-1098. https://doi.org/10.1016/j.jrp.2006.11.005

Lucas, R. E., Clark, A. E., Georgellis, Y., \& Diener, E. (2004). Unemployment alters the set point for life satisfaction. Psychological Science, 15(1), 8-13. https://doi.org/10.1111/j.0963-7214.2004.01501002.x

Luciano, E. C., \& Orth, U. (2017). Transitions in romantic relationships and development of self-esteem. Journal of Personality and Social Psychology, 112(2), 307-328. https://doi.org/10.1037/pspp0000109

Lugtig, P. (2014). Panel attrition: separating stayers, fast attriters, gradual attriters, and lurkers. Sociological Methods \& Research, 43(4), 699-723. https://doiorg.tilburguniversity.idm.oclc.org/10.1177/0049124113520305

Luhmann, M., \& Eid, M. (2009). Does it really feel the same? Changes in life satisfaction following repeated life events. Journal of Personality and Social Psychology, 97(2), 
363-381. https://doi.org/10.1037/a0015809

Luhmann, M., \& Eid, M. (2012). Studying reaction to repeated life events with discontinuous change models using HLM. In G. D. Garson (Ed.), Hierarchical linear modeling: Guide and applications (pp. 273289). Thousand Oaks, CA: Sage.

Luhmann, M., Fassbender, I., Alcock, M., \& Haehner, P. (2020, March 6). A dimensional taxonomy of perceived characteristics of major life events. PsyArXiv. https://doi.org/10.1037/pspp0000291

Luhmann, M., Hofmann, W., Eid, M., \& Lucas, R. E. (2012). Subjective well-being and adaptation to life events: A meta-analysis. Journal of Personality and Social Psychology, 102(3), 592-615. https://doi.org/10.1037/a0025948

Luhmann, M., Lucas, R. E., Eid, M., \& Diener, E. (2013). The prospective effect of life satisfaction on life events. Social Psychological and Personality Science, 4(1), 39-45. https://doi.org/10.1177/1948550612440105

Luhmann, M., Orth, U., Specht, J., Kandler, C., \& Lucas, R. E. (2014). Studying changes in life circumstances and personality: It's about time. European Journal of Personality, 28(3), 256-266. https://doi.org/10.1002/per.1951

Lykken, D., \& Tellegen, A. (1996). Happiness is a stochastic phenomenon. Psychological Science, 7(3), 186-189. https://doi.org/10.1111/j.1467-9280.1996.tb00355.x

Lyubomirsky, S., Tkach, C., \& DiMatteo, M. R. (2005). What are the differences between happiness and self-Esteem. Social Indicators Research, 78(3), 363-404. https://doi.org/10.1007/s11205-005-0213-y

Major, B., Spencer, S., Schmader, T., Wolfe, C., \& Crocker, J. (1998). Coping with negative stereotypes about intellectual performance: The role of psychological disengagement. Personality and Social Psychology Bulletin, 24(1), 34-50. https://doi.org/10.1177/0146167298241003 
MASKED (2021, March 22). Retrieved from https://osf.io/5jkhw/?view_only=230c45b8bb5446a9a8d08a6c6b41443f

McArdle, J. J., Ferrer-Caja, E., Hamagami, F., \& Woodcock, R. W. (2002). Comparative longitudinal structural analyses of the growth and decline of multiple intellectual abilities over the lifespan. Developmental Psychology, 38(1), 115-142. https://doi.org/10.1037/0012-1649.38.1.115

McKee-Ryan, F. M., Song, Z., Wanberg, C. R., \& Kinicki, A. J. (2005). Psychological and physical well-being during unemployment: A meta-analytic study. Journal of Applied Psychology, 90(1), 53-76. https://doi.org/10.1037/0021-9010.90.1.53

Mooi-Reci, I., \& Ganzeboom, H. B. (2015). Unemployment scarring by gender: Human capital depreciation or stigmatization? Longitudinal evidence from the Netherlands, 1980-2000. Social Science Research, 52, 642-658.

https://doi.org/10.1016/j.ssresearch.2014.10.005

Monroe, S. M., \& Harkness, K. L. (2005). Life stress, the "kindling" hypothesis, and the recurrence of depression: Considerations from a life stress perspective. Psychological Review, 112(2), 417-445. https://doi.org/10.1037/0033-295X.112.2.417

Neyer, F. J., \& Asendorpf, J. B. (2001). Personality-relationship transaction in young adulthood. Journal of Personality and Social Psychology, 81(6), 1190-1204. https://doi.org/10.1037//0022-3514.81.6.1190

Norlander, P., Ho, G. C., Shih, M., Walters, D. J., \& Pittinsky, T. L. (2020). The role of psychological stigmatization in unemployment discrimination. Basic and Applied Social Psychology, 42(1), 29-49. https://doi.org/10.1080/01973533.2019.1689363

OECD (2020). OECD Employment Outlook 2020: Worker security and the COVID-19 crisis, Paris: OECD Publishing. https://doi.org/10.1787/19991266.

OECD (2019). Employment protection legislation in OECD countries in 2019, Paris: OECD 
Publishing.

https://www.oecd.org/employment/emp/oecdindicatorsofemploymentprotection.htm

Oesch, D., \& Lipps, O. (2013). Does unemployment hurt less if there is more of it around? A panel analysis of life satisfaction in Germany and Switzerland. European Sociological Review, 29(5), 955-967. https://doi.org/10.1093/esr/jcs071

Orth, U., \& Luciano, E. C. (2015). Self-esteem, narcissism, and stressful life events: Testing for selection and socialization. Journal of Personality and Social Psychology, 109(4), 707-721. https://doi.org/10.1037/pspp0000049

Orth, U., \& Robins, R. W. (2014). The development of self-esteem. Current Directions in Psychological Science, 23(5), 381-387. https://doi.org/10.1177/0963721414547414

Orth, U., Erol, R. Y., \& Luciano, E. C. (2018). Development of self-esteem from age 4 to 94 Years: A meta-analysis of longitudinal studies. Psychological Bulletin, 144(10), 10451080. https://doi.org/10.1037/bu10000161

Orth, U., Trzesniewski, K. H., \& Robins, R. W. (2010). Self-esteem development from young adulthood to old age: A cohort-sequential longitudinal study. Journal of Personality and Social Psychology, 98(4), 645-658. https://doi.org/10.1037/a0018769

Otake, K., Shimai, S., Tanaka-Matsumi, J., Otsui, K., \& Fredrickson, B. L. (2006). Happy people become happier through kindness: A counting kindnesses intervention. Journal of Happiness Studies, 7(3), 361-375. https://doi.org/10.1007/s10902-005-3650-z

Pasupathi, M., Mansour, E., \& Brubaker, J. R. (2007). Developing a life story: Constructing relations between self and experience in autobiographical narratives. Human Development, 50(2-3), 85-110. https://doi.org/10.1159/000100939

Paul, K. I., \& Moser, K. (2009). Unemployment impairs mental health: Meta-analyses. Journal of Vocational Behavior, 74(3), 264-282. https://doi.org/10.1016/j.jvb.2009.01.001 
R Core Team. (2020). R: A language and environment for statistical computing. Vienna, Austria: R Foundation for Statistical Computing.

Reitz, A. K., Motti-Stefanidi, F., \& Asendorpf, J. B. (2016). Me, us, and them: Testing sociometer theory in a socially diverse real-life context. Journal of Personality and Social Psychology, 110(6), 908. https://doi.org/10.1037/pspp0000073

Reitz, A. K., Shrout, P. E., Denissen, J. J., Dufner, M., \& Bolger, N. (2020). Self-esteem change during the transition from university to work. Journal of Personality, 88(4), 689702. https://doi.org/10.1111/jopy.12519

Reitz, A. K., Weidmann, R., Wünsche, J., Bühler, J. Burriss, R. P., \& Grob, A. (2022). In good times and in bad: A longitudinal analysis of the impact of bereavement on selfesteem and life satisfaction in couples. European Journal of Personality. Advance online publication. https://doi.org/10.1177/08902070211054896

Roberts, B. W., Kuncel, N. R., Shiner, R., Caspi, A., \& Goldberg, L. R. (2007). The power of personality: The comparative validity of personality traits, socioeconomic status, and cognitive ability for predicting important life outcomes. Perspectives on Psychological science, 2(4), 313-345. https://doi.org/10.1111/j.1745-6916.2007.00047.x

Roberts, B. W., Wood, D., \& Smith, J. L. (2005). Evaluating five factor theory and social investment perspectives on personality trait development. Journal of Research in Personality, 39, 166-184. https://doi.org/10.1016/j.jrp.2004.08.002

Robins, R. W., Hendin, H. M., \& Trzesniewski, K. H. (2001). Measuring global self-esteem: Construct validation of a single-item measure and the Rosenberg Self-Esteem Scale. Personality and Social Psychology Bulletin, 27(2), 151-161. https://doi.org/10.1177/0146167201272002

Robins, R. W., Tracy, J. L., Trzesniewski, K., Potter, J., \& Gosling, S. D. (2001). Personality correlates of self-esteem. Journal of Research in Personality, 35(4), 463-482. 
https://doi.org/10.1006/jrpe.2001.2324

Rosenberg, M. (1965). Society and the adolescent self-image. Princeton, NJ: Princeton University Press.

Ryan, R. M., \& Deci, E. L. (2000). Self-determination theory and the facilitation of intrinsic motivation, social development, and well-being. American Psychologist, 55(1), 68. https://doi.org/10.1037/0003-066X.55.1.68

Salmela-Aro, K., \& Nurmi, J. E. (2007). Self-esteem during university studies predicts career characteristics 10 years later. Journal of Vocational Behavior, 70(3), 463-477. https://doi.org/10.1016/j.jvb.2007.01.006

Sameroff, A. (1975). Transactional models in early social relations. Human Development, 18(1-2), 65-79. https://doi.org/10.1159/000271476

Sameroff, A. (2010). A unified theory of development: A dialectic integration of nature and nurture. Child Development, 81(1), 6-22. https://doi.org/10.1111/j.14678624.2009.01378.x

Scherpenzeel, A. C., \& Das, M. (2010). “True” longitudinal and probability-based Internet panels: Evidence from the Netherlands. In M. Das, P. Ester, \& L. Kaczmirek (Eds.), Social and Behavioral Research and the Internet: Advances in Applied Methods and Research Strategies (pp. 77-104). Boca Raton, FL: Taylor \& Francis.

Schmillen, A., \& Möller, J. (2010). Determinants of lifetime unemployment. A micro data analysis with censored quantile regressions. Institute for the Study of Labor (IZA), Research Paper Series, 4751.

Schwartz, S. H. (1999). A theory of cultural values and some implications for work. Applied Psychology, 48(1), 23-47. https://doi.org/10.1111/j.1464-0597.1999.tb00047.x

Sinclair, S. J., Blais, M. A., Gansler, D. A., Sandberg, E., Bistis, K., \& LoCicero, A. (2010). Psychometric properties of the Rosenberg Self-Esteem Scale: Overall and across 
demographic groups living within the United States. Evaluation and the Health Professions, 33(1), 56-80. https://doi.org/10.1177/0163278709356187

Stutzer, A., \& Frey, B. S. (2006). Does marriage make people happy, or do happy people get married? Journal of Socio-Economics, 35(2), 326-347. https://doi.org/10.1016/j.socec.2005.11.043

Tetzner, J., Becker, M., \& Baumert, J. (2016). Still doing fine? The interplay of negative life events and self-esteem during young adulthood. European Journal of Personality, 30(4), 358-373. https://doi.org/10.1002/per.2066

Thomas, C., Benzeval, M., \& Stansfeld, S. A. (2005). Employment transitions and mental health: An analysis from the British household panel survey. Journal of Epidemiology and Community Health, 59(3), 243-249. https://doi.org/10.1136/jech.2004.019778

Trzesniewski, K. H., Donnellan, M. B., \& Robins, R. W. (2003). Stability of self-esteem across the life span. Journal of Personality and Social Psychology, 84(1), 205-220. https://doi.org/10.1037/0022-3514.84.1.205

Trzesniewski, K. H., Donnellan, M. B., Moffitt, T. E., Robins, R. W., Poulton, R., \& Caspi, A. (2006). Low self-esteem during adolescence predicts poor health, criminal behavior, and limited economic prospects during adulthood. Developmental Psychology, 42(2), 381-390. https://doi.org/10.1037/0012-1649.42.2.381

U.S. Bureau of Labor Statistics (2019). Number of jobs, labor market experience, and earnings growth: Results from a national longitudinal survey. https://www.bls.gov/news.release/pdf/nlsoy.pdf

Palumbo, T. J (2010). Dynamics of economic well-being: Spells of Unemployment. 20042007. Current Population Reports, P70-120. Washington, DC: U.S. Census Bureau. Unanue, W., Gómez, M. E., Cortez, D., Oyanedel, J. C., \& Mendiburo-Seguel, A. (2017). Revisiting the link between job satisfaction and life satisfaction: The role of basic 
psychological needs. Frontiers in Psychology, 8(680), 1-17. https://doi.org/10.3389/fpsyg.2017.00680

Van den Broeck, A., Ferris, D. L., Chang, C. H., \& Rosen, C. C. (2016). A review of selfdetermination theory's basic psychological needs at work. Journal of Management, 42(5), 1195-1229. https://doi.org/10.1177/0149206316632058

van der Meer, P. H., \& Wielers, R. (2016). Happiness, unemployment and self-esteem. (SOM Research Reports; Vol. 16016). University of Groningen, SOM research school.

van Scheppingen, M. A., \& Leopold, T. (2020). Trajectories of life satisfaction before, upon, and after divorce: Evidence from a new matching approach. Journal of Personality and Social Psychology, 119(6), 1444-1458. https://doi.org/10.1037/pspp0000270 von Scheve, C., Esche, F., \& Schupp, J. (2017). The emotional timeline of unemployment: Anticipation, reaction, and adaptation. Journal of Happiness Studies, 18(4), 1231-1254. https://doi.org/10.1007/s10902-016-9773-6

Wagenaar, A. F., Kompier, M. A. J., Houtman, I. L. D., van den Bossche, S. N. J., \& Taris, T. W. (2015). Who gets fired, who gets re-hired: the role of workers' contract, age, health, work ability, performance, work satisfaction and employee investments. International Archives of Occupational and Environmental Health, 88(3), 321-334. https://doi.org/10.1007/s00420-014-0961-6

Wagner, J., Orth, U., Bleidorn, W., Hopwood, C. J., \& Kandler, C. (2020). Toward an integrative model of sources of personality stability and change. Current Directions in Psychological Science, 29(5), 438-444.

Wanberg, C. R. (2012). The individual experience of unemployment. Annual Review of Psychology, 63, 369-396. https://doi.org/10.1146/annurev-psych-120710-100500 Warr, P. B. (1987). Work, unemployment and mental health. Oxford, England: Clarendon Press. 
Warr, P. B. (2007). Work, happiness, and unhappiness. Mahwah, NJ: Lawrence Erlbaum

Warr, P., Jackson, P., \& Banks, M. (1982). Duration of unemployment and psychological well-being in young men and women. Current Psychological Research, 2(1-3), 207214. https://doi.org/10.1007/BF03186762

Wille, B., \& De Fruyt, F. (2014). Vocations as a source of identity: Reciprocal relations between big five personality traits and RIASEC characteristics over 15 years. Journal of Applied Psychology, 99(2), 262-281. https://doi.org/10.1037/a0034917

Wilson T. D., \& Gilbert D. T. (2005). Affective forecasting. Knowing what to want. Current Directions in Psychological Science, 14(3), 131-134. https://doi.org/10.1111/j.09637214.2005.00355.x

Winkelmann, L., \& Winkelmann, R. (1998). Why are the unemployed so unhappy? Evidence from panel data. Economica, 65(257), 1-15. https://doi.org/10.1111/1468-0335.00111

Winkelmann, R. (2009). Unemployment, social capital, and subjective well-being. Journal of Happiness Studies, 10(4), 421-430. https://doi.org/10.1007/s10902-008-9097-2

Wojciszke, B., Baryla, W., Parzuchowski, M., Szymkow, A., \& Abele, A. E. (2011). Selfesteem is dominated by agentic over communal information. European Journal of Social Psychology, 41(5), 617-627. https://doi.org/10.1002/ejsp.791

Wrzus, C., \& Roberts, B. W. (2017). Processes of personality development in adulthood: The TESSERA framework. Personality and Social Psychology Review, 21(3), 253-277. https://doi.org/10.1177/1088868316652279

Yap, S. C. Y., Anusic, I., \& Lucas, R. E. (2012). Does personality moderate reaction and adaptation to major life events? Evidence from the British Household Panel Survey. Journal of Research in Personality, 46(5), 477-488. https://doi.org/10.1016/j.jrp.2012.05.005 


\section{Footnotes}

${ }^{1}$ Our decision to choose a five-year interval was based on previous research that found this interval to be long enough to capture anticipatory effects (which can occur as early as 2-3 years prior to the event), adaptation effects, and to disentangle stable and temporary effects (Clark et al., 2008; Denissen et al., 2019; Luhmann et al., 2013). We preferred the 5year interval over a monthly metric, which would have rendered the coefficients too small.

${ }^{2}$ For the demographic variables female gender, education, income, marital status, Dutch heritage, age, self-esteem, and life satisfaction we took participants' first value and imputed missing values, using the R-package mice (Version 3.11.1). We then proceeded to select only a subsample of LISS participants who ever reported being employed. Using the "nearest neighbor" algorithm of the matchit R-package (Version 4.3.2), we used these variables to created matched samples that people who did experience a first work transition and those who did not, using propensity scores that depended on the above-described variables. For unemployment, matching was fully successful but for employment, there were still major differences for age and marital status so we included these variables as control variables in the analyses. In the resulting models, we no longer included a selection effect because propensity score matching is aimed at removing the influence of selection effects.

${ }^{3}$ We excluded an outlier from the correlations between self-esteem and job satisfaction, which was $r=.62$. It stems from the 2010 data collection, when there were less than 40 data points for this correlation. We excluded this correlation from our presentation of the correlation ranges, as it is not representative for the rest of the waves (ranged between .22 and .39). 